
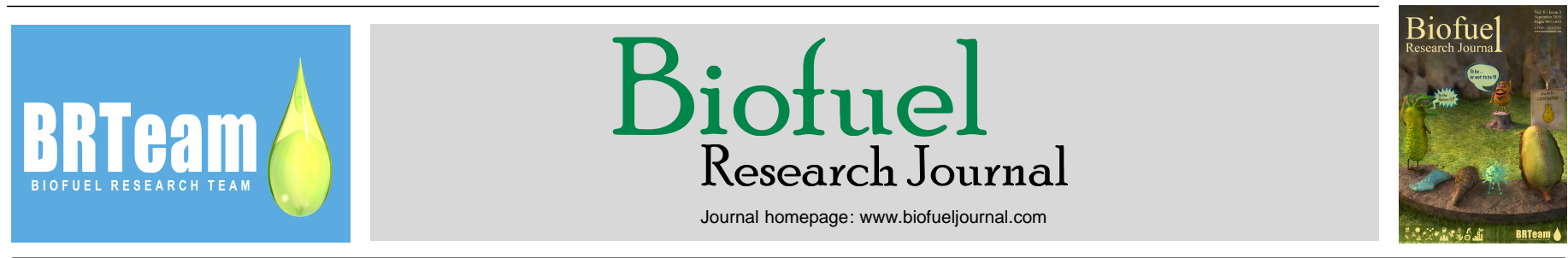

Original Research Paper

\title{
Candida rugosa lipase nanoparticles as robust catalyst for biodiesel production in organic solvents
}

\author{
Rohit Kumar Sharma ${ }^{1,2, \ldots}$, Crystal A. O'Neill ${ }^{1,3}$, Hector A.R. Ramos ${ }^{1,2}$, Bibek Thapa ${ }^{1,4, \#}$, Vanessa C. Barcelo-Bovea ${ }^{1,3}$, \\ Kavita Gaur ${ }^{1,3}$, Kai Griebenow ${ }^{1,3, *}$
}

${ }^{I}$ Molecular Sciences Research Center, University of Puerto Rico, 1390 Ponce de Leon Avenue, Suite 2, San Juan, Puerto Rico 00926-2614, United States.

${ }^{2}$ Department of Environmental Science, University of Puerto Rico, Río Piedras campus, 17 Ave Universidad STE 1701, San Juan, Puerto Rico 00925-2537,

United States.

${ }^{3}$ Department of Chemistry, University of Puerto Rico, Río Piedras campus, 17 Ave Universidad STE 1701, San Juan, Puerto Rico 00925-2537, United States.

${ }^{4}$ Department of Physics, University of Puerto Rico, Río Piedras campus, 17 Ave Universidad STE 1701, San Juan, Puerto Rico 00925-2537, United States.

\section{HIGHLIGHTS}

$>$ Formation of the Candida rugosa lipase nanoparticles by nanoprecipitation method.

$>$ Crosslinking and conjugation of Candida rugosa lipase nanoparticles.

$>$ Biodiesel production by utilizing brown grease and used cooking oil.

$>$ Kinetics of the Candida rugosa lipase nanoparticles in $\mathrm{n}$-heptane and 1,4-dioxane. $>$ Biodiesel production in organic solvents ( $\mathrm{n}-$ heptane, 1,4-dioxane, and t-butanol).

\section{GRAPHICAL ABSTRACT}

Candida rugosa lipase nanoparticle (left) conjugated to magnetic iron oxide nanoparticle (right)

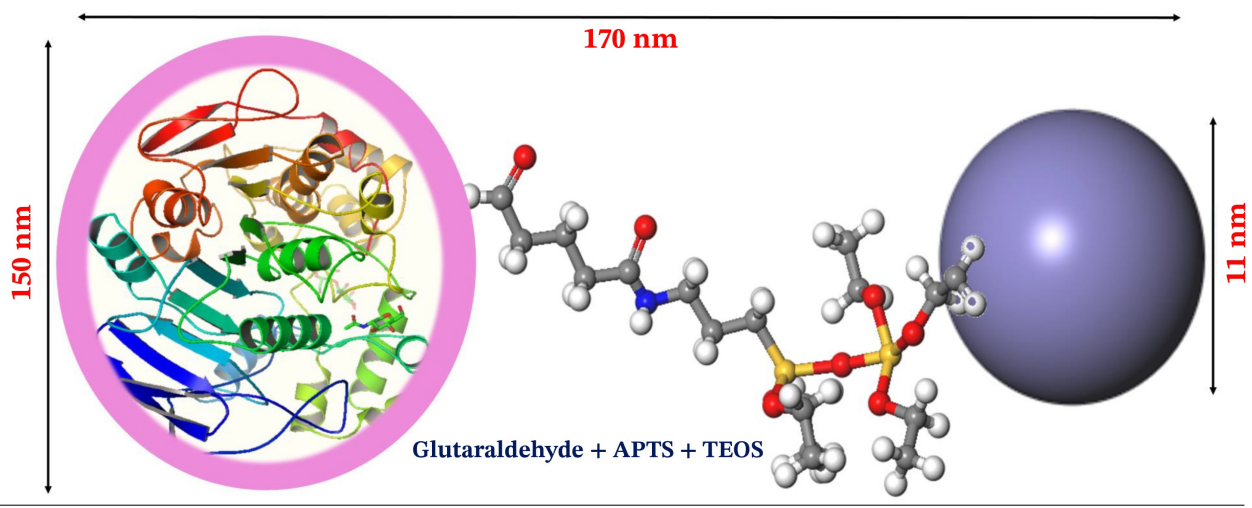

\begin{abstract}
Inexpensive but resourceful sources of lipids, for example, used cooking oil (UCO) and brown grease (BG), which often contain large amounts of free fatty acids (FFA), are difficult to convert into biodiesel economically and in good yield. Candida rugosa lipase nanoparticles (cNP) were formed first and subsequently cross-linked nanoparticles (CLNP) were obtained by crosslinking of them. Alternatively, cNP were conjugated to magnetic nanoparticles (mNP) to achieve a cNP-mNP conjugate. All three formulations were employed in three different organic solvents (n-heptane, 1,4-dioxane, and t-butanol) to produce biodiesel using BG and UCO in the transesterification reaction with ethanol and methanol. The radii of nanoparticles (NP) were 5.5, 75, $100,85 \mathrm{~nm}$ for $\mathrm{mNP}$, cNP, CLNP, and cNP-mNP, respectively, as measured by scanning/transmission electron microscopy and dynamic light scattering. The catalytic efficiency $\left(\mathrm{K}_{\mathrm{cat}} / \mathrm{K}_{\mathrm{M}}\right)$ of cNP, CLNP, and cNP-mNP was increased ca. $-25,-68,-176$ folds in n-heptane and -35,-131,-262 folds in 1,4-dioxane compared to the lyophilized lipase in the model transesterification reaction of p-nitrophenyl palmitate (PNPP) with ethanol. In biodiesel formation, the best performance with $100 \%$ conversion of BG was achieved under optimum conditions with cNP-mNP, ethanol at a 1:3 molar ratio of lipid-to-alcohol, NP at a 1:0.1 weight ratio of lipid-to-enzyme, and water at a 1:0.04 weight ratio of enzyme-to-water at $30{ }^{\circ} \mathrm{C}$ for $35 \mathrm{~h}$. The operational stability of the CLNP and cNP-mNP was sustained even after five consequent biodiesel batch conversions while $50 \%$ and $82 \%$ residual activity (storage stability) were retained after $40 \mathrm{~d}$.

(c) 2019 BRTeam. All rights reserved.
\end{abstract}

* Corresponding author at: Tel.: +1-787-408-2760

E-mail address: kai.griebenow@gmail.com

Present address: ¥ Comprehensive Cancer Center, University of Puerto Rico, San Juan, PR 00935, USA. \# Advanced Imaging Research Center, The University of Texas Southwestern Medical Center, 5323 Harry Hines Blvd, Dallas, TX 75390-8568, USA.

Please cite this article as: Sharma R.K., O'Neill C.A., Ramos H.A.R., Thapa B., Barcelo-Bovea V.C., Gaur K., Griebenow K. Candida rugosa lipase nanoparticles as robust catalyst for biodiesel production in organic solvents. Biofuel Research Journal 23 (2019) 1025-1038. DOI: 10.18331/BRJ2019.6.3.3 


\begin{tabular}{|ll|}
\hline Abbreviations & \\
APTS & (3-Aminopropyl) triethoxysilane \\
BCA & Bicinchoninic acid \\
BG & Brown grease \\
CLEA & Cross-linked enzyme aggregates \\
CLNP & Crosslinked nanoparticles of Candida rugosa lipase \\
cNP & Candida rugosa lipase nanoparticles \\
& Candida rugosa nanoparticles formed by using 1,4- \\
cNP-D & dioxane \\
& Candida rugosa nanoparticles formed by using THF \\
cNP-T & cNP conjugated to mNP \\
cNP-mNP & cNP conjugated to mNP formed by using 1,4- \\
cNP-mNP-D & dioxane \\
& cNP conjugated to mNP formed by using THF \\
cNP-mNP-T & Candida rugosa lipase \\
CRL & Dynamic light scattering \\
DLS & Fatty acid alkyl esters \\
FAAE & Fatty acid ethyl esters \\
FAEE & Fatty acid methyl esters \\
FAME & Free fatty acids \\
FFA & Fourier transform infrared \\
FTIR & Magnetic nanoparticles of iron oxide \\
mNP & Methyl- $\beta$-cyclodextrin \\
M $\beta C D$ & Nanoparticles \\
NP & Polydispersity index \\
PDI & p-nitrophenyl palmitate \\
PNPP & Paranitrophenol, 4-Nitrophenol \\
PNP & Scanning electron microscopy \\
SEM & Tertiary butanol \\
t-butanol & Transmission electron microscopy \\
TEM & Tetrahydrofuran \\
TEOS & Used cooking oil \\
THF & X-ray diffraction \\
UCO & \\
VSM & \\
XRD & \\
& \\
\hline
\end{tabular}

\section{Introduction}

Nanobiocatalysis is a fast-developing area of nanotechnology in which materials sciences and biotechnology combine synergistically to improve the stability and catalytic performance of biocatalysts. In recent years, numerous reports have been published where tailor-made nanostructures (nanofibers, carbon nanotubes, magnetic nanoparticles-mNP, etc.) were utilized in various biomedical applications (Mahdavi et al., 2013; Xu et al., 2014) including as support for enzyme immobilization (Kim et al., 2008; Verma et al., 2013). From several available nanostructures, $\mathrm{mNP}$ appear particularly promising for chemical conversions including biodiesel production (Wang et al., 2009; Xie and Ma, 2009; Dussan et al., 2010; Yu et al., 2013). These customized mNP of few nanometers in scale are appropriate for biodiesel production because large loading of the enzyme (lipase) is possible since nanoparticles (NP) offer a large surface-to-volume ratio. Moreover, compared to other nanostructures, $\mathrm{mNP}$ possess the discrete feature of magnetism, which make enzyme recovery, cleaning, storage, and reuse effortless. Better control of reaction initiation, termination, and flexibility in scaling the process are additional advantages. Drastic improvements in activity, shelf-life, and operational stability of lipase immobilized on $\mathrm{mNP}$ have been reported in the formation of various products (Dyal et al., 2003; Rebelo et al., 2010; Xun et al., 2012).

In our previous work, we demonstrated that improvement in the enzyme performance without immobilization is possible when lipase from Rhizopus arrhizus was formulated in nanoparticulate form to synthesize biodiesel in nheptane (Sharma et al., 2018). However, despite the substantial improvement in the enzymatic activity, such a NP system could be further optimized by crosslinking of the lipase NP or linking them to a material with useful properties, i.e., mNP. Applications of enzymes in chemical processes obviously should be economically viable. Enzyme immobilization on $\mathrm{mNP}$ is a nontrivial process requiring multiple steps and therefore, is not exactly cheap per se. Creation of cross-linked enzyme aggregates (CLEA), in contrast, is a very simple and comparatively economical process (Sheldon et al., 2005). Consequently, this enzyme technology has found a foothold in several industrial applications (Sheldon, 2010). Potential disadvantages include large particle size $(5-50 \mu \mathrm{m})$ and consequently diffusional limitations in mass transfer, which could restrict CLEA in achieving a high degree of catalysis (Sheldon et al., 2005; Adlercreutz, 2013). To ameliorate such mass transfer problems associated with particle size, some reports have been published where better control of CLEA particle size was achieved by varying the crosslinker amount, $\mathrm{pH}$, salt, and other variables ( $\mathrm{Yu}$ et al., 2006). We suggest that CLEA can be further improved by using NP as starting material.

Biodiesel produced by conventional transesterification using a chemical catalyst requires raw materials of better and uniform quality and high input of temperature for processing when compared to inorganic catalysts (sodium/potassium hydroxides or alkoxides) (Fjerbaek et al., 2009). This causes two major problems in sustainable biodiesel production. First, biodiesel production is frequently based on oils from food crops and this threatens food supply and elevates costs (Schenk et al., 2008). Second, when feedstocks high in free fatty acids (FFA) (waste oils, algal lipids, rice bran oil, animal fat, etc.) are utilized for biodiesel production, then such feedstock must first be esterified by an acidic catalyst and subsequently transesterified by a base catalyst (Fjerbaek et al., 2009; Ribeiro et al., 2011). This contributes to the formation of several side products (glycerol, salts, alkaline wastewater, etc.), whose filtration in the downstream process increases the cost and chances to contaminate the final product (Ribeiro et al., 2011). Most of these problems, however, can be minimized or avoided by utilizing lipases as biocatalysts. Different types of lipases are available for industrial scale biodiesel production but they mostly are moderately expensive and supplied in liquid or non-immobilized form. Furthermore, lipases supplied at reasonable costs are frequently quite crude. Therefore, these cannot be recycled batch-wise and make the enzymatic process expensive. Consequently, lipase use is impractical from a commercial standpoint. This problem, though, can be amended by either utilizing inexpensive lipase of higher activity or by immobilizing them on an inert surface to enable reuse (Fjerbaek et al., 2009).

Lipase from Candida rugosa (CRL) gained interest during the last few decades because of its structure (Grochulski et al., 1994; de Maria et al., 2006), high activity under both, aqueous and nonaqueous conditions (Linko et al., 1995), and broad specificity (Benjamin and Pandey, 1998). Ample literature is available on hydrolytic and synthetic reactions driven by CRL including biodiesel production (Benjamin and Pandey, 1998; Kojima et al., 2004; Park et al., 2008; Shao et al., 2008; Kuo et al., 2013; Kuo et al., 2015). Nevertheless, few reports have been published on CRL transesterification of FFA rich feedstocks (Shah et al., 2004; Kartal et al., 2011). One of the main reasons for this ambiguity might be due to the variation in the composition of commercial crude preparations of CRL because different lots from the same supplier may have massive discrepancies in protein and lactose amount, and isoenzyme profiles (de Maria et al., 2006). Because of the existence of the heterogeneity in composition, purification of CRL became necessary to allow for drawing meaningful comparison of the kinetic reactions. Up to $99 \%$ conversion of canola oil was achieved with a purified isoform of CRL in a transesterification reaction (Linko et al., 1995), and 100\% fatty acid methyl esters (FAME) formation was accomplished by utilizing activated bleaching earth in the presence of crude CRL (Kojima et al., 2004). When CRL was immobilized on iron mNP, high operational stability was achieved (47\% residual activity after $180 \mathrm{~d}$ and $30 \%$ activity after 7 batches of biodiesel formation) (Wang et al., 2009). Similarly, when CLEA of CRL were employed in the esterification reactions of longer fatty acids and alcohols, a higher yield of the different esters was obtained and $40 \%$ of activity was retained after 15 catalytic conversions (Kartal et al., 2011).

Herein, we aim to explore the efficacy of CRL NP in biodiesel production using FFA-rich waste lipid sources. We synthesized three different categories of NP from purified CRL by a nanoprecipitation method using tetrahydrofuran and 1,4-dioxane as organic precipitants. In the first category, we synthesized CRL NP, while in the second, we crosslinked these NP during the nanoprecipitation process. Finally, in the third, 
we conjugated CRL NP onto functionalized iron oxide NP. For biodiesel synthesis, we selected used cooking oil (UCO) and brown grease (BG) as our model lipid sources. While plenty of reports are available on UCO-derived biodiesel, BG-based biodiesel is still in early stages of research and development. To optimize the conditions (highest yield in least time) in biodiesel synthesis, a different combination of solvents (n-heptane, 1,4dioxane, and tertiary butanol (t-butanol) and acyl acceptor (methanol and ethanol) were used with our nanobiocatalysts. Our data show that BG served as an excellent feedstock for biodiesel production with our lipase formulations. Furthermore, immobilized NP (cross-linked and conjugated) produced a higher yield of biodiesel with enhanced operational stability when compared to the purified lyophilized CRL.

\section{Materials and Methods}

\subsection{Chemicals}

Crude lipase from $C$. rugose VII, p-nitrophenol (PNP), p-nitrophenyl palmitate (PNPP), methyl- $\beta$-cyclodextrin (M $\beta C D)$, methyl heptadecanoate, tetraethyl orthosilicate (TEOS), (3-aminopropyl) triethoxysilane (APTS), glutaraldehyde, n-heptane, t-butanol, methanol, ethanol, Supelco® 37 component FAME mix, fatty acid ethyl esters (FAEE) C4-C24 even carbon saturated were purchased from Sigma-Aldrich (St. Louis, MO, USA). Sodium Oleate $(\mathrm{NaOL},>97.0 \%$ ) was purchased from TCI America (Portland, OR, USA). 1-Octadecene (ODE, 90\%), Hexane (anhydrous, 95\%), Oleic acid (99\%) were purchased from Alfa Aesar (Ward Hill, MA, USA). Tetrahydrofuran (THF) and 1,4-dioxane of HPLC grade were purchased from ACROS Organics (NJ, USA). All solvents were in the anhydrous form (Sure/Seal bottles-water content below $0.025 \%$ ) and used without further drying. Filtered and dehydrated samples of UCO and BG were obtained from the Organic Power, LLC, Puerto Rico. The molecular weight of the BG and UCO was 832 and 858 $\mathrm{g} / \mathrm{mol}$, respectively, as calculated from their saponification value (Talebi et al., 2014). Nearly the same values were reported by the supplier.

2.2. Purification of the crude CRL, optimum $\mathrm{pH}$ and temperature of activity, and protein determination

Purification of the crude CRL was performed as described in the literature (Rúa and Ballesteros, 1994; Liou et al., 1998). Estimation of the activity at a different stage of purification was done by olive oil emulsion method (Pinsirodom and Parkin, 2001). Purity was estimated by the Coomassie stained SDS-PAGE gel (12-20\% gradient) using VisionWorksLS 7.0 software (UVP, GelDoc-It, Imagining System, USA). The fold of purification and yield at different steps of purification was also calculated. To get the optimum values of $\mathrm{pH}$ and temperature, purified lipase was treated as reported in the literature (Falony et al., 2006). Different buffers of variable pH but same ionic strengths were used to change the $\mathrm{pH}$. The protein concentration was determined by the Pierce $^{\mathrm{TM}}$ BCA Protein Assay (Pierce, USA) as per the manufacturer's instructions in 96 well microplate using a Multiskan ${ }^{\text {TM }}$ FC Microplate reader (ThermoFisher, Waltham, MA, USA)

\subsection{Preparation of Candida rugosa lipase nanoparticles ( $c N P$ )}

The cNP samples were obtained by the nanoprecipitation method as previously described (Langer et al., 2003). Briefly, purified lyophilized CRL powder and $\mathrm{M} \beta C D$ were combined at a 1:4 weight ratio $(\mathrm{CRL} / \mathrm{M} \beta C D)$ and dissolved in phosphate buffer (100 mM, pH 7.5). The final concentration of the CRL in the solution was $4 \mathrm{mg} / \mathrm{mL}$. The resulting solution was stirred with a magnetic stir bar at room temperature until the solution homogenized. The water-miscible solvents, THF or 1,4-dioxane was added at a defined rate of 2.0 $\mathrm{mL} / \mathrm{min}$ by a syringe pump (Fisher Scientific, MA, USA) directly to the enzyme solution at a 1:4 volume ratio (CRL-solution/solvent). The subsequent suspension of NP was stirred for $30 \mathrm{~min}$ and then centrifuged at $3,100 \times \mathrm{g}$ and $20{ }^{\circ} \mathrm{C}$ for $15 \mathrm{~min}$ (Eppendorf, $5810 \mathrm{R}$, Hamburg, Germany). The supernatant was discarded, and the obtained pellet was washed 3 times with the same solvent used in the nanoprecipitation process. After washing, the pallet was flash-frozen in liquid nitrogen and lyophilized overnight using a FreeZone 2.5liter benchtop freeze dryer (Labconco, MO, USA) at a condenser temperature of $-50{ }^{\circ} \mathrm{C}$ and a pressure of 0.05 mbar. We optimized the CRL-to-M $\beta C D$ ratio by using 1:1, 1:2, 1:4, 1:6, and 1:8 w:w ratios. The ratio at which the best specific activity was achieved was subsequently used in all experiments. Also, we experimentally tested the effect of the protein concentration and solvent addition rate on NP yield, activity, and size.

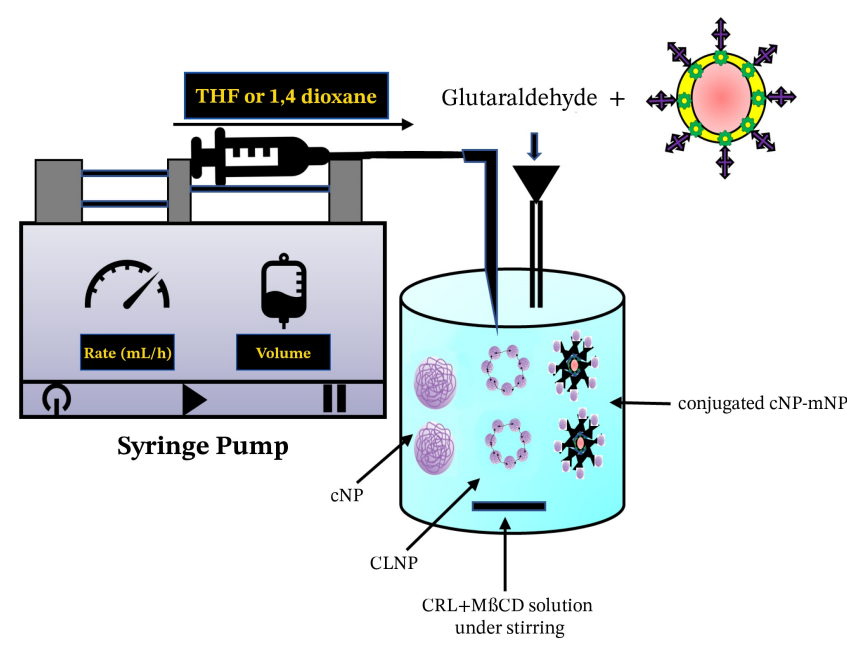

Scheme 1. CRL NP formation (cNP, CLNP, and immobilization of cNP on functionalized $\mathrm{mNP})$.

\subsection{Preparation of cross-linked nanoparticles (CLNP)}

The synthesis of cross-linked nanoparticles (CLNP) was the same as described in cNP formation. The only difference was that after solvent addition, 25\% glutaraldehyde solution was added at a 1:200 molar ratio (CRL/glutaraldehyde). After that, the suspension was left for crosslinking under stirring for $16 \mathrm{~h}$ at $4{ }^{\circ} \mathrm{C}$. Next, the sample was centrifuged as described above and washed with potassium phosphate buffer $(100 \mathrm{mM}$, $\mathrm{pH}$ 7.5) thrice to remove any unbound/excess crosslinker and then lyophilized. The optimum molar ratio of CRL-to-crosslinker and crosslinking time was experimentally evaluated.

\subsection{Synthesis of magnetic nanoparticles $(m N P)$}

The mNP were synthesized by a thermal decomposition method. For this, $4.8 \mathrm{~g}$ of iron oleate $(\mathrm{FeOL})$ and $846 \mu \mathrm{L}$ of oleic acid $(\mathrm{OA})$ were dissolved in $17 \mathrm{~mL}$ of 1 -octadecene (ODE) in a 3-neck round bottom flask. After degassing the solution for $15 \mathrm{~min}$, it was heated to $320^{\circ} \mathrm{C}$ at the heating rate of $3.3{ }^{\circ} \mathrm{C} / \mathrm{min}$ under nitrogen followed by aging for $2 \mathrm{~h}$ at 320 ${ }^{\circ} \mathrm{C}$. Then, the solution was cooled to room temperature and was precipitated using a mixture of hexane and acetone in a 1:1 volume ratio. The product was centrifuged for $30 \mathrm{~min}$ at $13,946 \times \mathrm{g}$ at $10{ }^{\circ} \mathrm{C}$ by using a Sorval Lynx 4000 centrifuge (Thermo Scientific, Waltham, USA) at first, and then was centrifuged using acetone for four times to obtain the OA free bare mNP.

\subsection{Surface modification of $m N P$ and conjugation of $c N P$ to $m N P$}

The surface modification of bare mNP was accomplished by TEOS and APTS as previously reported without any modifications (Dussan et al., 2010). For conjugation of the $\mathrm{cNP}$ to $\mathrm{mNP}$, functionalized $\mathrm{mNP}$ were added in 1:0.5 weight ratio $(\mathrm{CRL} / \mathrm{mNP})$ directly into the $\mathrm{cNP}$ suspension after 30 min of the nanoprecipitation step. Next, glutaraldehyde (as mentioned previously) was added to the suspension (cNP and mNP mixture) and conjugation was completed by gentle shaking using a nutating mixer at 24 $\mathrm{rpm}$ and a tilt angle of $20^{\circ}$ (Fisher Scientific, MA, USA) for $16 \mathrm{~h}$ at $4{ }^{\circ} \mathrm{C}$ The suspension was subjected to centrifugation at $3,100 \times \mathrm{g}$ for $15 \mathrm{~min}$ at 4 ${ }^{\circ} \mathrm{C}$. The supernatant was collected to analyze the unbound lipase $\mathrm{NP}$ and the pellet of the conjugated NP were recovered by magnetic decantation. The recovered pellet was washed 3 times with potassium phosphate buffer $(100$ $\mathrm{mM}, \mathrm{pH} 7.5$ ) by centrifugation and each time the supernatant was collected to analyze any leaching of the cNP from the conjugated assembly. Finally, the conjugated NP were lyophilized the same way as the cNP. To estimate 


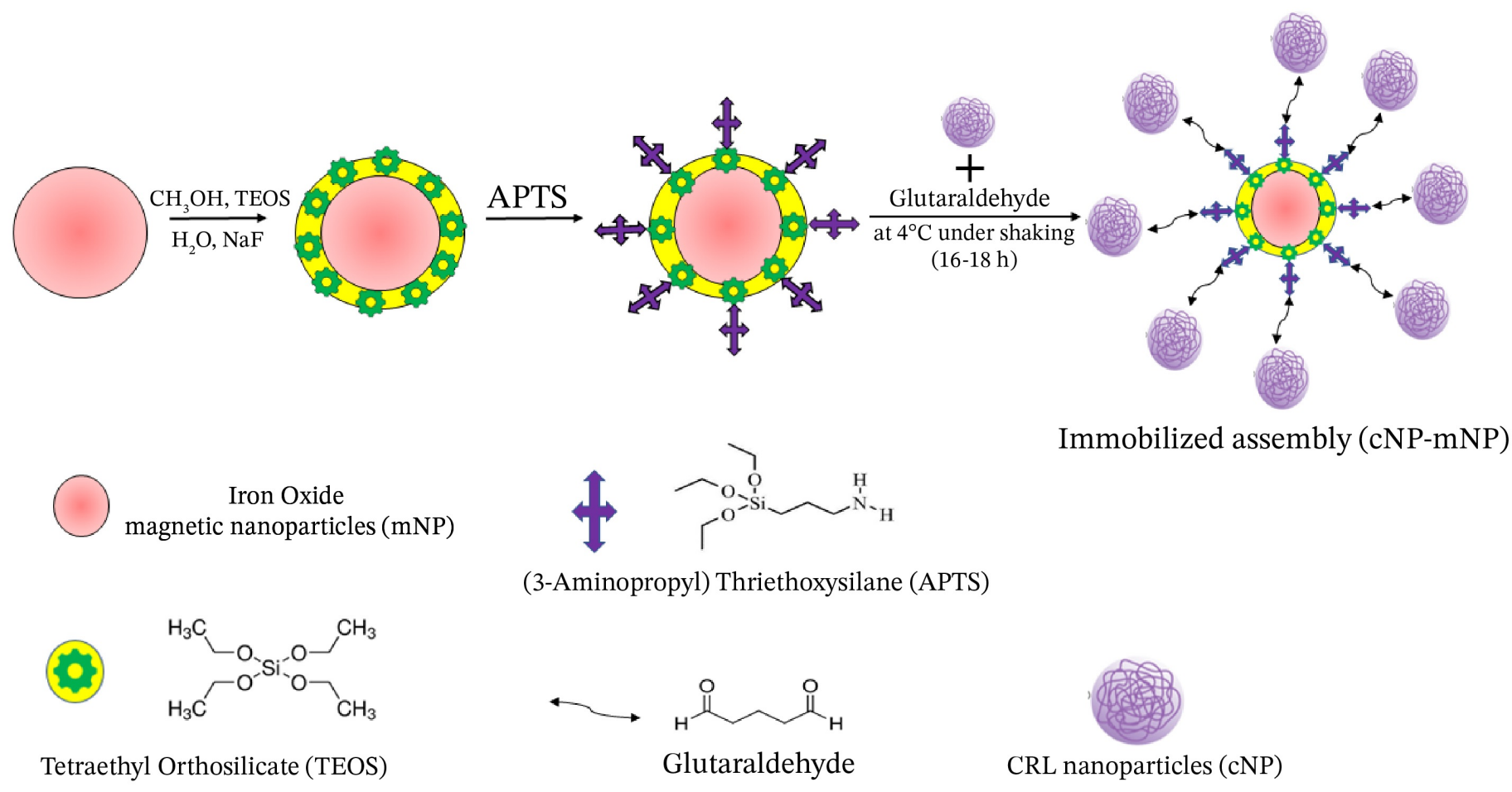

Scheme 2. Surface modification of mNP and conjugation of cNP to mNP

the efficiency of the conjugation (total amount of cNP attached to mNP), the total protein concentration in the initial step of nanoprecipitation was determined by BCA as mentioned previously. This amount was subtracted from the total protein found in the supernatant during recovery and subsequent washing (as mentioned before). The difference in protein concentration was used to estimate the efficiency of the conjugation.

\subsection{Characterization of the NP samples}

\subsubsection{Scanning electron microscopy (SEM)}

SEM analysis of cNP, CLNP, and cNP-mNP was performed using a JEOL $5800 \mathrm{LV}$ scanning electron microscope (JEOL, MA, USA) at $20 \mathrm{kV}$ to study the morphology of the samples. To prepare the samples, $1 \mathrm{mg}$ of each type of NP sample in powdered form were evenly distributed on ultrathin carbon film and coated with gold for $10 \mathrm{sec}$ by using a DV-502A Denton vacuum coater (Denton Vacuum, Inc., NJ, USA).

\subsubsection{Transmission electron microscopy (TEM)}

TEM was employed to observe the size, morphology, and crystallinity of bare $\mathrm{mNP}$ and cNP-mNP using JEOL JEM-2100F transmission electron microscope (JEOL, MA, USA) operating at $200 \mathrm{kV}$. For the preparation of TEM grid sample, $25 \mu \mathrm{L}$ of bare mNP and NP-mNP samples diluted in hexane were dropped on carbon film on 200 mesh, Copper grid (Ted Pella, Inc.), and allowed to dry overnight.

\subsubsection{Size, polydispersity, and zeta potential}

The size and polydispersity distribution of the cNP, CLNP, and cNP-mNP were determined by dynamic light scattering (DLS) using a DynaProTitan instrument (Wyatt Technology, CA, USA). For cNP, $0.5 \mathrm{mg}$ sample was suspended in $2 \mathrm{~mL}$ of THF followed by sonication for $60 \mathrm{sec}$ prior to the measurements. CLNP and cNP-mNP $(5 \mathrm{mg} / \mathrm{mL})$ were dispersed in nanopure water and sonicated until a good suspension was obtained. Analysis of the data was performed using Dynamic 6.7.6 software. Zeta potential data was collected on Zetasizer Nanoseries (Malvern Instruments Ltd., UK) using polystyrene capillary disposable cuvettes.

\subsubsection{Vibration sample magnetometry (VSM)}

The field dependent magnetic measurement $(\mathrm{M}-\mathrm{H})$ at room temperature was measured by vibration sample magnetometry (VSM) in the physical property measurement system (PPMS) (Quantum Design Inc., CA, USA). The powder sample of $5 \mathrm{mg}$ of bare $\mathrm{mNP}$ and cNP-mNP were used in the polypropylene VSM powder sample holder and the (M-H) measurement was run in the range $\pm 1.5 \mathrm{~T}$ of the applied field.

\subsection{5. $X$-ray diffraction $(X R D)$}

Powdered X-ray diffraction (XRD) of bare mNP and cNP-mNP were obtained by a Rigaku SmartLab X-Ray diffractometer using $\mathrm{CuK} \alpha(\lambda=$ $1.5406 \AA$ ) operating at $40 \mathrm{KV}$ and $44 \mathrm{~mA}$, scanning ranges from $10^{\circ}$ to $90^{\circ}$.

\subsubsection{Fourier transform infrared (FTIR)}

FTIR spectroscopy was used to follow the surface modification from bare $\mathrm{mNP}$ to cNP-mNP. All samples were measured in the solid-state as $\mathrm{KBr}$ pellets and spectra were collected using a Nicolet iS 50 FT-IR Spectrometer (ThermoFisher Scientific, WI, USA). Samples were homogenized by using an agate mortar and pestle. The concentration of the sample in $\mathrm{KBr}$ was kept at $0.2-0.25 \%$. Powders were pressed into pellets using a SpectraTech Macro-Micro $\mathrm{KBr}$ Die Kit and a Carver 12-ton hydraulic press (Wabash, IN, USA). A total of 256 acquisitions were performed at a resolution of $4 \mathrm{~cm}^{-1}$ over the range $4000-500 \mathrm{~cm}$. For each scan, the spectra were corrected for the background by using a blank $\mathrm{KBr}$ pellet.

\subsection{Determination of enzyme kinetics}

Initial rates for the product formation in the transesterification of $\mathrm{p}$ nitrophenyl palmitate (PNPP) with ethanol by lyophilized CRL and all NP 
under different conditions were determined using anhydrous n-heptane and 1,4dioxane as reported earlier with some modifications (Sharma et al., 2018). Typical reactions conditions were: 5-mL of PNPP (10 mM dissolved in either $\mathrm{n}$-heptane or 1,4-dioxane), $10 \mathrm{mg}$ of CRL-lyophilized or NP, $0.3 \mathrm{~mL}$ of ethanol, and $4 \mu \mathrm{L}$ of water in a 7-mL screw-cap vial were placed on an orbital shaker (New Brunswick Scientific Co., N.J.) at $30{ }^{\circ} \mathrm{C}$ under reciprocal agitation at 250 strokes/min. Samples $(50-200 \mu \mathrm{l})$ were periodically withdrawn and product (pnitrophenol) was extracted with $0.1 \mathrm{~N} \mathrm{NaOH}$. Optical density was measured in an automatic microplate reader (Tecan Infinite M200, Switzerland) at a wavelength of $410 \mathrm{~nm}$. The control experiment was performed in the same manner but without adding the enzyme. No absorbance at $410 \mathrm{~nm}$ was observed in the absence of the enzyme. The concentration of p-nitrophenol in the transesterification reaction was determined by creating the standard curve of $p$ nitrophenol in the tested solvent. For the activity calculations, reaction progress curve of concentration of p-nitrophenol released vs. reaction time was employed.

To determine the Michaelis-Menten parameters $\left(\mathrm{K}_{\mathrm{M}}, \mathrm{V}_{\max }, \mathrm{k}_{\mathrm{cat}}\right.$, and $\left.\mathrm{k}_{\text {cat }} / \mathrm{K}_{\mathrm{M}}\right)$, initial rates were determined in n-heptane and 1,4-dioxane for 2.5 to $30 \mathrm{mM}$ of PNPP and the $\mathrm{v}_{0}$ data were fitted using the nonlinear regression curve fitting function of Prism 7, Graph-Pad Software. The quality of the regression fit for velocity $v s$. substrate plots was considered in the acceptable range when the $\mathrm{R}^{2}$ value was at least $90 \%$ as calculated by the software. To test the accurateness of the fits, random $\mathrm{K}_{\mathrm{M}}, \mathrm{V}_{\max }$ values of some samples were calculated by LineweaverBurke plots (data not shown). No significant difference in values was observed.

\subsection{Thermal stability of the NP}

Thermal stability assays were performed in aqueous and nonaqueous conditions with the same amount of lipase in each sample. For the aqueous system, samples were mixed in phosphate buffer $(100 \mathrm{mM}, \mathrm{pH} 7.5)$ and incubating at different temperatures ranging from $20{ }^{\circ} \mathrm{C}$ to $70{ }^{\circ} \mathrm{C}$ for $30 \mathrm{~min}$ using a water bath (MyBath 4L, Benchmark Scientific, NJ). Next, residual activity was determined by olive oil titration method as mentioned earlier. For the activity in the nonaqueous system, NP were treated in the same way as aqueous, the only difference was that $n$-heptane was used instead of phosphate buffer. Results are presented in Supplementary fïle: Figure S6.

\subsection{Synthesis of biodiesel}

The transesterification reactions were carried out in $15-\mathrm{mL}$ screw-cap vial at $30{ }^{\circ} \mathrm{C}$ on an orbital shaker at $250 \mathrm{rpm}$. The composition of the reaction mixtures, unless otherwise stated, was lipids of either UCO or BG, methanol or ethanol in 1:3 molar ratio (lipid/alcohol), NP (protein content) in 1:0.1 weight ratio (lipid/enzyme), water in 1:0.04 weight ratio (enzyme/water), and $2 \mathrm{~mL}$ of either solvent (n-heptane/1,4-dioxane/t-butanol) to solubilize the lipids completely. Samples were periodically withdrawn, mixed with methyl heptadecanoate which served as an internal standard and analyzed by gas chromatography/mass spectrometry (GC/MS). The fatty acid alkyl esters (FAAE) conversion was calculated as described in the literature (Schober et al., 2006). To obtain the maximum conversion of lipids into FAAE, the effects of enzyme amount, water content, various molar ratios of acyl acceptors (methanol and ethanol), and solvent were studied.

\subsection{Gas chromatography/mass spectrometry (GC/MS) analysis}

Identification and analysis of fatty acid esters were performed as reported earlier without any modifications (Sharma et al., 2018).

\subsection{Operational and storage stability}

For operational stability experiment, samples were recovered after each batch of biodiesel formation. Lyophilized CRL, cNP, and CLNP were recovered by centrifugation at $3,100 \times \mathrm{g}$ for $10 \mathrm{~min}$, while cNP-mNP were recovered by using magnetic decantation. All samples were washed up to 3 times with n-heptane and dried in an incubator $\left(30^{\circ} \mathrm{C}\right)$ for $4-5 \mathrm{~h}$ before using them in the next catalytic cycle.

For storage stability, residual activity of the formulations was determined by transesterification reaction ( $\mathrm{n}$-heptane) as explained in 'Determination of enzyme kinetics' section above. Activity of the samples stored at $4{ }^{\circ} \mathrm{C}$ were determined in $1,7,15,25,30$, and $40 \mathrm{~d}$ and for residual activity calculation, activity obtained on day 1 was considered $100 \%$.

\subsection{Statistical analysis}

All statistical data were analyzed by GraphPad Prism 7.0 (GraphPad Software, La Jolla, CA). One-way and Two-way ANOVA test were performed as per the requirement of the analysis.

Symbol meaning: $\mathrm{ns}$ (not significant) $\mathrm{P}>0.05, * \mathrm{p} \leq 0.05, * * \mathrm{p} \leq 0.01$, $* * * \mathrm{p} \leq 0.001, * * * * \mathrm{P} \leq 0.0001$.

\section{Results and Discussion}

\subsection{Enzyme optimization}

The versatility of CRL in various substrate transformations is evident from the number of published papers (Benjamin and Pandey, 1998). Slight variations are reported in the literature in the optimization of process parameters, e.g., $\mathrm{pH}$ and temperature, which might be due to the presence of various isoforms (Benjamin and Pandey, 2001). Since the CRL we commercially obtained was crude, we followed and optimized purification conditions described in the literature (Rúa and Ballesteros, 1994; Liou et al., 1998) and achieved a highly active single monomeric form with a relative $\mathrm{M}_{\mathrm{W}}$ of $60 \mathrm{kDa}$ as estimated by SDS-PAGE (Supplementary file: Table S1, Fig. S1). This preparation was used to determine the optimum $\mathrm{pH}$ of lipase activity and the maximum activity was obtained at $\mathrm{pH} 7.5$ (Supplementary file: Fig. S2a), which is consistent with the literature (Benjamin and Pandey, 1998). The optimum temperature of maximum activity was found to around $30{ }^{\circ} \mathrm{C}$ but at 25 to $35^{\circ} \mathrm{C}$ no significant drop in activity was observed (Supplementary file: Fig. S2b), which indicates that CRL is stable around $25-35{ }^{\circ} \mathrm{C}$. These findings are also in line with the previous reports (Tsai and Dordick, 1996; Benjamin and Pandey, 1998).

\subsection{CRL NP formation}

The performance of enzymes under non-aqueous conditions has been improved by creating nano-sized enzyme particles (Sharma et al., 2018) or by immobilizing the enzyme on nanomaterials ( $\mathrm{Li}$ et al., 2013). This is applicable to biodiesel synthesis. For example, a drastic improvement in the performance of lipases has been reported in biodiesel production when their immobilization was carried out on nanostructures (Cipolatti et al., 2014) Herein, we compare various formulations of lipase combining these concepts in their effectiveness in biodiesel formation.

The size and internal structure of enzyme particles are correlated to internal mass transfer and this is established as an important factor in the rate of the reaction under non-aqueous conditions (Kamat et al., 1992) Nano-precipitation has been used previously to obtain enzyme NP for nonaqueous conversions (Langer et al., 2003). We obtained lipase NP by precipitation and first identified the best solvent for the nanoprecipitation of CRL. Several solvents were tested (acetone, acetonitrile, 1-butanol, 1,4dioxane, DMSO, ethanol, ethyl acetate, 1-propanol, and THF). However, consistent narrow size-range NP were obtained by precipitation with 1,4 dioxane and THF only. The optimized experimental conditions are shown in Table 1 and the scheme of the nanoprecipitation procedure is shown in Scheme 1. Conditions listed in Table 1 were obtained after several trial and error experiments in which one-factor-at-a time was changed. First, the effect of CRL concentration on NP yield, residual activity, and size was determined (Supplementary file: Table S2). Different concentrations (2$20 \mathrm{mg} / \mathrm{mL}$ ) of CRL in buffer were prepared. The volume and rate of solvent addition were kept the same as listed in Table 1 . The best yield of NP was obtained when the protein concentration was $4 \mathrm{mg} / \mathrm{mL}$. Increasing the concentration further resulted in the formation of aggregates, while at a lower concentration, the NP yield was low. The size of the NP increased at increasing protein concentration while the residual activity did not change significantly up to $10 \mathrm{mg} / \mathrm{mL}$ and then decreased. This might be due to the formation of large buffer insoluble aggregates. Once the optimum concentration was established, further optimization was performed by varying the volume ratio of solvent-to-buffer. At a 1:4 volume ratio, the maximum yield of NP was obtained. This ratio was found to provide a good yield of CRL NP. At lower and higher ratios, heterogeneity in particle size 
Table 1.

Optimum conditions of cNP formation.

\begin{tabular}{llllll}
\hline${\text { CRL volume }(\mathbf{m L})^{\mathbf{a}}}^{\text {a }}$ & Solvent & Solvent volume $(\mathbf{m L})$ & Rate of solvent addition $(\mathbf{m L} / \mathbf{h})$ & NP yield $^{\mathbf{b}}$ & Residual activity $^{\mathbf{c}}$ \\
\hline 25 & 1,4-dioxane & 100 & 120 & $98 \pm 5 \%$ & $100 \pm 10 \%$ \\
25 & THF & 100 & 120 & $95 \pm 8 \%$ & $95 \pm 7 \%$ \\
\hline
\end{tabular}

${ }^{\mathrm{a}} \mathrm{CRL}$ concentration was $4 \mathrm{mg} / \mathrm{mL}$ in $100 \mathrm{mM}$ phosphate buffer at $\mathrm{pH} 7.5$.

${ }^{\mathbf{b}}$ The NP yield was calculated from the difference of the actual weight of CRL taken initially and the total weight of the NP recovered after the process.

${ }^{\mathbf{c}}$ Residual activity was calculated by an olive oil titration method by re-dissolving the NP in the appropriate buffer. The experiments were performed in triplicate, the results averaged, and the standard deviations calculated. The experiment demonstrates that no irreversible structural changes leading to aggregation were caused by the process.

distribution increased and residual activity was poor (data not shown). In another set of optimization experiments, the effect of the solvent addition rate on NP activity and PDI was determined (Supplementary file: Table S3). At a solvent addition rate of $80 \mathrm{~mL} / \mathrm{h}$ the NP were very polydisperse and the PDI could not be measured. The PDI started improving as the solvent addition rate was increased. At $120 \mathrm{~mL} / \mathrm{h}$, PDI was the lowest and the residual activity was at the maximum. Increasing the rate further did not further improve the NP PDI or activity and the yield was poor (data not shown). These observations are in good agreement with those of Langer et al. (2003).

Once CRL concentration, solvent volume, and rate of solvent addition were optimized, we focused on increasing the activity of the enzyme NP by adding the excipient $\mathrm{M} \beta \mathrm{CD}$. We formed NP with varying ratios of lipase-to-M $\beta C D$ by co-dissolving $\mathrm{M} \beta \mathrm{CD}$ with $\mathrm{CRL}$ prior to subjecting it to the solvent precipitation step using the parameters listed in Table 1 . The unbound $M \beta C D$ was removed from the NP by repeated cycles of centrifugation and washing with 1,4-dioxane or THF. The size (radius) and the relative activity of the obtained NP were plotted for each lipase-to-M $\beta C D$ ratio (Supplementary file: Fig. S3a). At the 1:4 ratio, maximum activity was achieved, and the radius of the NP was $75 \mathrm{~nm}$. $\mathrm{M} \beta \mathrm{CD}$ has been used by our group before to improve enzyme activity in organic solvents and to obtain nano-sized protein particles (Griebenow et al., 1999; Montalvo et al., 2008; Sharma et al., 2018).

CLNP were synthesized by adding glutaraldehyde during cNP formation as shown in Scheme 1. To study the effect of crosslinking on cNP properties, the CLNP were prepared with different molar amounts of the glutaraldehyde. The obtained NP were examined in terms of activity and yield (Supplementary file: Fig. S3b). At molar ratio of 1:200 of CRL/glutaraldehyde, maximum activity and yield of the CLNP were obtained. Increasing the glutaraldehyde amount further caused activity and yield to decrease, which might be due to the interference of the excess amount of the cross-linker with important residues of the protein (Sheldon et al., 2005). The crosslinking reaction was also optimized at using different reaction temperatures and times. Best results were obtained when the reaction was performed at $4{ }^{\circ} \mathrm{C}$ for $16 \mathrm{~h}$ under gentle stirring (Supplementary fille: Table S4).

Subsequently, conjugation of cNP with surface modified mNP was carried out as shown in Schemes 1 and 2. Optimization of the conditions was performed to achieve maximum conjugation efficiency. Three different weight ratios of 1:1, 1:0.5, and 1:0.25 were tested to see the effect of cNP attachment to mNP (Supplementary file: Fig. S3c). The percentage of cNP attachment to $\mathrm{mNP}$ was found to be 92,94 , and $80 \%$ (w/w), respectively. However, statistical analysis revealed no significant difference between the 1:0.5 and 1:1 ratio. Therefore, the 1:0.5 ratio was used in subsequent experiments.

\subsection{NP Characterization}

The NP morphology, size, PDI, and zeta potential were inspected by SEM, TEM, and DLS. SEM/TEM images give a good idea of the morphology of the NP but due to the invasive nature of the methods, DLS data provide more accurate size data. Figure 1 shows the SEM, DLS, and TEM images of the different NP. Visual inspection by SEM showed a homogeneous distribution of the cNP with a narrow size distribution. No significant difference in the morphology of the cNP synthesized using THF (data not shown) or 1,4-dioxane (Fig. 1a) was observed. DLS data confirm these findings because particle sizes follow a Gaussian distribution in a single peak (Fig. 1b) with a low PDI (Supplementary file: Table S5) and thus size distribution of the cNP. In CLNP, an increase in the particle size was observed, which was expected as the formation of CLNP was achieved by crosslinking of cNP. The resulted increment of the particle size is evident in the Figure $1 \mathrm{c}$ and a comparatively large distribution of the particles by DLS were also observed (Fig. 1d) as compared to the cNP data. Oleic acid-coated mNP appears spherical with an average size of $11 \mathrm{~nm}$ (Fig. 1e). High-resolution TEM shows the lattice fringes with a characteristic spacing of $2.3 \AA$ associated with (311) planes of magnetite $\left(\mathrm{Fe}_{3} \mathrm{O}_{4}\right)$ (Fig. 1f). This phase formation was also observed in powder XRD patterns (Fig. 2b) depicting the typical peaks of magnetite $\left(\mathrm{Fe}_{3} \mathrm{O}_{4}\right)$ (JCPDS file no. 79-0418). In the case of the cNP-mNP conjugate, the particle size and distribution were the same as cNP (inset of Fig. 1g). These findings fit with the theoretical predictions that mNP, which size is very small (Figs. 1e and 1f), add little to the size of cNP.

It is important to point out here that our strategy is different from immobilization reported by others (Yong et al., 2008; Xie and Ma, 2009; Wang et al., 2012) where lipase was immobilized on the activated NP in aqueous conditions. Using such an approach, only marginal or no increment in the size of immobilized CRL on $\mathrm{Fe}_{3} \mathrm{O}_{4} \mathrm{NP}$ was observed by DLS and TEM (Wang et al., 2012), which is expected because lipases are soluble in the aqueous phase and therefore immobilized in form of a thin layer on the carrier surface (Fernandez-Lorente et al., 2008). The diameter of immobilized CRL on $\mathrm{Fe}_{3} \mathrm{O}_{4}$ was reported with $100 \mathrm{~nm}$ (Wang et al., 2012). In contrast, we construct a conjugate of $\mathrm{cNP}$ and $\mathrm{mNP}$ in a nano-nano fashion. In contrast to immobilization methods, impact of conjugation chemistry on lipase in the cNP is expected to be minimum in contrast to lipase denaturation triggered by direct coating on the carrier (Montero et al., 1993; Mei et al., 2003; Fernandez-Lorente et al., 2008; Wang et al., 2012). The lipase in cNP is already protected from structural changes because it is dehydrated and the subsequent chemistry is carried out in a non-aqueous solvent, a fact that has been used for many years to obtain active enzymes in organic solvents (Dordick, 1992; Klibanov, 2001).

The zeta potential value of cNP, CLNP, and cNP-mNP were found to be $-16,-25$, and $-20 \mathrm{mV}$, respectively (Supplementary file: Table S5). This indicates that the cNP-mNP suspension might not be very stable because values between +30 and $-30 \mathrm{mV}$ signify a tendency of the particles to aggregate. However, this is more relevant in medical applications but not in catalysis when the suspensions are constantly agitated. Previous reports on the zeta potential of CRL lipase in solution and as immobilized form reported nearly the same values (Solanki and Gupta, 2011)

The magnetization hysteresis $(\mathrm{M}-\mathrm{H})$ curves of bare $\mathrm{mNP}$ and the cNP$\mathrm{mNP}$ conjugate are shown in Figure 2a. Both samples are showing a strong magnetic response with a saturation magnetization (MS) of 137 and 41 $\mathrm{emu} / \mathrm{g}$ of Fe for bare $\mathrm{mNP}$ and the cNP-mNP conjugate, respectively. The reduction of MS in cNP-mNP after functionalization is attributed to the presence of the magnetically dead layer consisting of cNP and to the spincanting effect on the surface of cNP (Kim et al., 2011; Thapa et al., 2018, 2019). The inset of Figure 2a shows the remanence (MR) and coercivity (HC) values of both samples which are considerably low with $3.7 \mathrm{emu} / \mathrm{g}$ of Fe and -0.0015 Tesla, respectively, indicating superparamagnetic behavior (Wang et al., 2016).

Figure $2 \mathrm{~b}$ shows the XRD patterns of $\mathrm{mNP}$ and the cNP-mNP conjugate. The diffraction peaks observed were indexed to the reflection planes of cubic inverse spinel $\mathrm{Fe}_{3} \mathrm{O}_{4}$ corresponding to the (220), (311), (400), (422), (511) (440), and (533) planes (Mahmoudi et al., 2011; Thapa et al., 2017) and were observed to be of highly crystalline quality. This indicates that the crystalline structure and phase of $\mathrm{mNP}$ were retained 

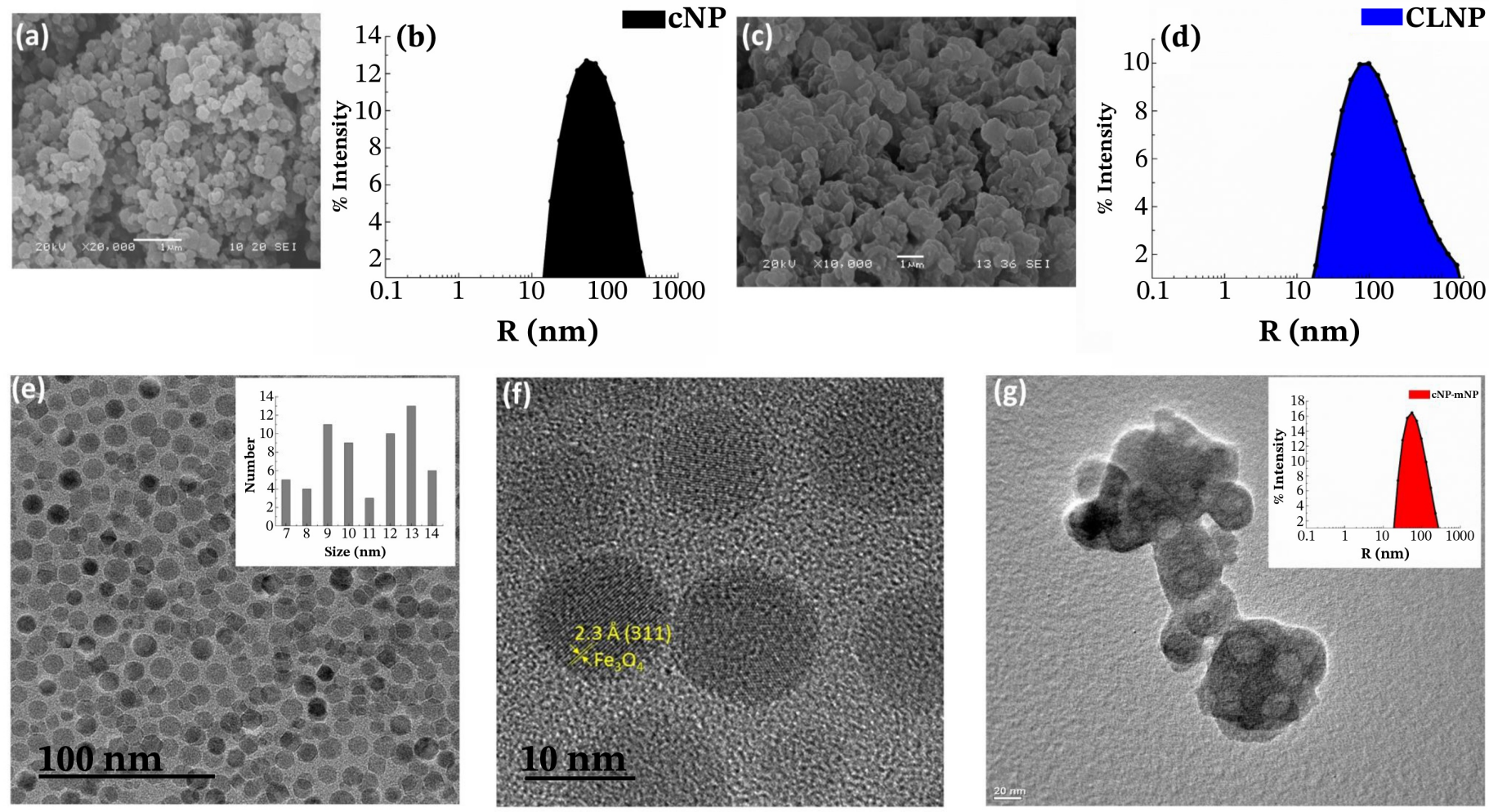

Fig. 1. Morphology and size (hydrodynamic radii) determination by scanning electron microscopy (SEM) and dynamic light scattering (DLS) measurements. (a and b) cNP; (c and d) CLNP; (e) transmission electron micrographs (TEM) of mNP with inset showing the size distribution profile; (f) high-resolution transmission electron micrographs of mNP; (g) $\mathrm{cNP}$-mNP conjugate with inset showing the size distribution.

during conjugation. The decreased intensity in the XRD patterns in cNP-mNP compared to the bare $\mathrm{mNP}$ indicates the successful conjugation to $\mathrm{cNP}$ as the latter are not ordered. Both VSM and XRD data confirm that the cNP-mNP conjugate has the characteristics of $\mathrm{mNP}$ and $\mathrm{cNP}$, which in turn indicates that these were successfully conjugated.

FT-IR characterization of all samples (cNP, CLNP, and cNP-mNP) was performed (Fig. 2c). A strong signal observed at $570 \mathrm{~cm}^{-1}$ in cNP-mNP corresponds to the $\mathrm{Fe}-\mathrm{O}$ bond stretching vibration (Mahmoudi et al., 2011). This vibration confirms the presence of $\mathrm{mNP}$ in the sample. Since cNP were modified with TEOS and APTS, two distinguish modes at $1050 \mathrm{~cm}^{-1}$ related to $\mathrm{Si}-\mathrm{O}-\mathrm{Fe}$ bonds of TEOS and at around $800 \mathrm{~cm}^{-1}$ largely due to the bending vibration of $-\mathrm{NH}_{2}$ groups present in the APTS were observed (Dussan et al., 2010). The protein amide I and amide II modes at around $1660 \mathrm{~cm}^{-1}$ and 1540 $\mathrm{cm}^{-1}$ were also observed, respectively. Both of these distinguishing peaks were evidently observed in all the three analyzed samples. The broad $\mathrm{O}-\mathrm{H}$ stretching vibration near $3420 \mathrm{~cm}^{-1}$ is tentatively ascribed to the adsorbed $\mathrm{H}_{2} \mathrm{O}$ in the sample (Dussan et al., 2010).

\subsection{Enzyme activity and kinetics of the lipase NP}

Excellent catalytic performance of CRL has been reported in several organic solvents in various transformation reactions (Hirata et al., 1990; Tsai and Dordick, 1996). Dramatic increases in the reaction rate by utilizing solvent engineering approaches, by adding activators, or simply by optimizing the water content/activity in the reaction medium have been reported (Hirata et al., 1990; Parida and Dordick, 1993; Benjamin and Pandey, 1998). Of these, optimizing the water content in the reaction medium seems to be one of the most prominent factors in achieving optimum kinetics. Crude and purified CRL may respond differently with respect to the water addition because crude CRL powder has a varying composition of the different isoforms (Tsai and Dordick, 1996; de Maria et al., 2006). Therefore, optimizing the conditions with respect to purified isoforms becomes necessary (Rúa and Ballesteros, 1994). Considering all the critical points mentioned above, we first optimized the minimum amount of water required to achieve optimum NP activity. Maximum activity was achieved at $4 \%$ water (of the total enzyme amount, w/w) in both n-heptane and 1,4-dioxane.

The specific activities of cNP, CLNP, and cNP-mNP formed by precipitation with 1,4-dioxane or THF were analyzed with respect to purified lyophilized CRL (Supplementary file: Fig. S4). In all cases, the activity of the NP (cNP, CLNP, and cNP-mNP) synthesized by precipitation with 1,4-dioxane or THF was the same showing that the precipitation solvent did not influence activity. Specific lipase activity increased by around 14, 20, and 40 folds, respectively, in n-heptane compared to lyophilized CRL and similarly in 1,4-dioxane. No significant difference in activities of lyophilized CRL in n-heptane and 1,4-dioxane was observed (Supplementary file: Fig. S4). However, higher activity of all nanoparticulate formulations was observed in 1,4-dioxane. It is important to mention here that the data were obtained with the optimum amount of water present in the reaction. Without water addition, higher activity was found in $\mathrm{n}$-heptane (data not shown). This is expected because water activity is generally higher in non-polar solvents than polar solvents (Zaks and Klibanov, 1988a). When low water reactions are performed, the enzymatic reaction depends on the water adsorbed to the enzyme $\left(a_{w}\right)$. At the same $a_{w}$, water activity is higher in hydrophobic solvents (n-heptane) than in hydrophilic ones (1,4-dioxane) and usually in the former, a better enzymatic activity is achieved. Therefore, adjustment in the optimum amount of water to perform the reaction in various organic solvents is indispensable to provide the desired conformational mobility to catalysts in a nonaqueous environment (Parida and Dordick, 1993).

Next, a detailed kinetics analysis was performed using lipase NP. The Michaelis-Menten parameters were obtained from measurements at increasing substrate concentrations (Supplementary file: Fig. S5). The findings of this experiment indicate that the kinetics in the organic solvents followed Michaelis-Menten kinetics under the conditions employed. The $\mathrm{v}_{\max }, \mathrm{K}_{\mathrm{M}} \mathrm{k}_{\mathrm{cat}}$, and $\mathrm{k}_{\text {cat }} / \mathrm{K}_{\mathrm{M}}$ values obtained are listed in Table 2. In n-heptane, lower values of $\mathrm{K}_{\mathrm{M}}$ and $\mathrm{k}_{\text {cat }}$ were obtained than in 1,4-dioxane. In other words, substrate affinity was better in $n$-heptane while active side chemistry was better in 1,4-dioxane. To understand the case better, we calculated 

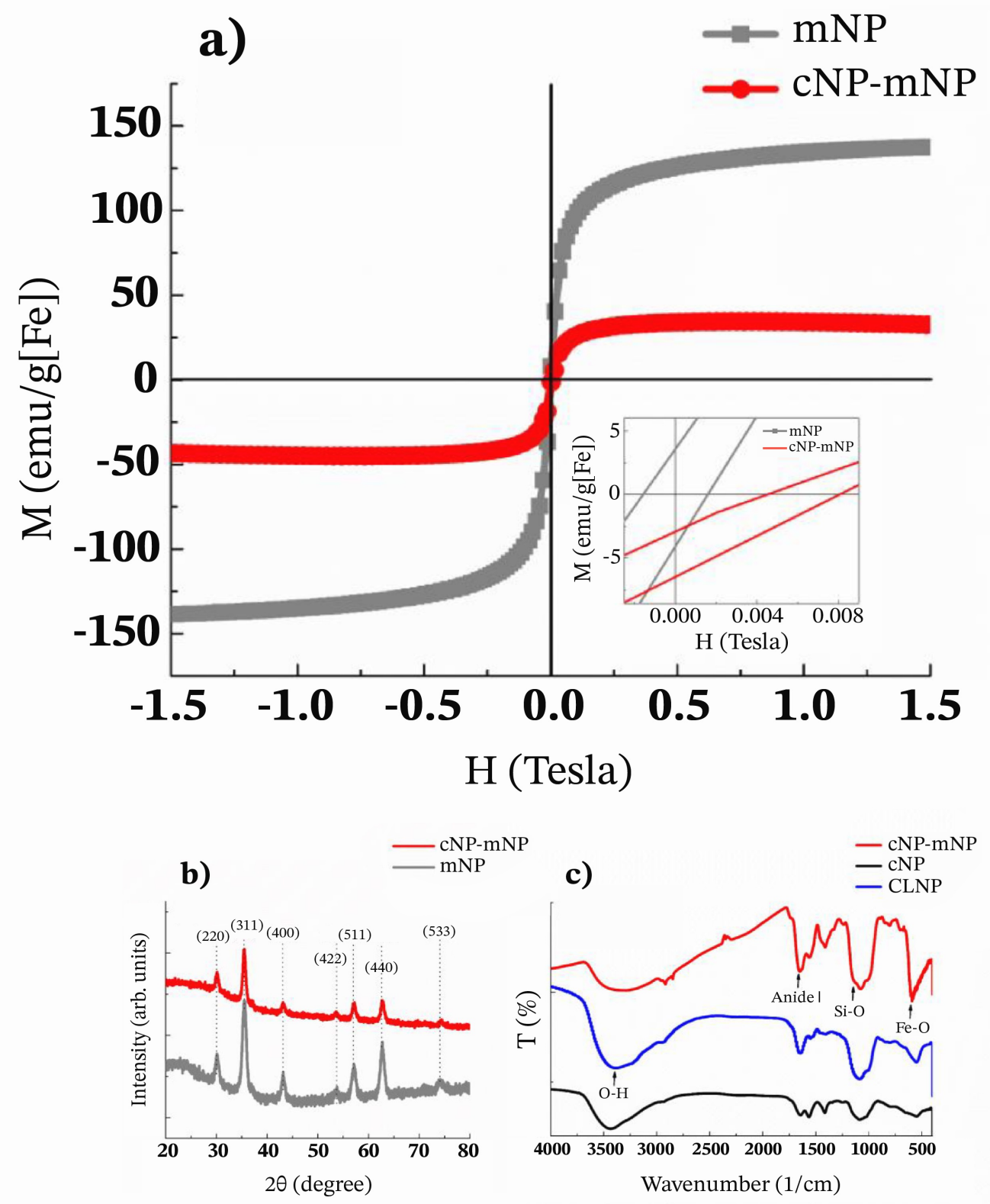

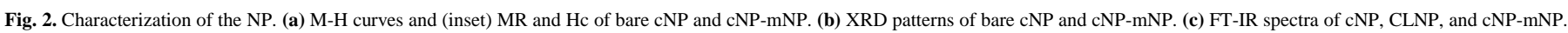

Table 2.

Kinetic parameters of NP in n-heptane and 1,4-dioxane.

\begin{tabular}{|c|c|c|c|c|c|c|c|c|}
\hline \multirow[b]{2}{*}{ Sample } & \multicolumn{4}{|c|}{ n-heptane } & \multicolumn{4}{|c|}{ 1,4-dioxane } \\
\hline & $\mathbf{K}_{\mathbf{M}}(\mathbf{m} \mathbf{M})$ & $\begin{array}{c}\mathbf{V}_{\max } \\
\left(\mathbf{m M} \mathbf{m i n}^{-1}\right)\end{array}$ & $\mathbf{k}_{\text {cat }}\left(\min ^{-1}\right)$ & $\begin{array}{c}\mathbf{k}_{\mathrm{ca}} / \mathbf{K}_{\mathbf{M}} \\
\left(\mathbf{m M}^{-1} \mathbf{m i n}^{-1}\right)\end{array}$ & $\mathbf{K}_{\mathbf{M}}(\mathbf{m M})$ & $\begin{array}{c}\mathbf{V}_{\max } \\
\left(\mathbf{m M} \mathbf{m i n}^{-1}\right)\end{array}$ & $\mathbf{k}_{\text {cat }}\left(\mathbf{m i n}^{-1}\right)$ & $\begin{array}{c}\mathbf{k}_{\mathrm{cat}} / \mathbf{K}_{\mathrm{M}} \\
\left(\mathbf{m M}^{-1} \mathbf{m i n}^{-1}\right)\end{array}$ \\
\hline CRL-lyophilized & $5.44 \pm 3.26$ & $0.03 \pm 0.005$ & 0.991 & 0.182 & $14.5 \pm 8.86$ & $0.05 \pm 0.013$ & 1.53 & 0.106 \\
\hline $\mathrm{cNP}$ & $3.70 \pm 1.31$ & $0.51 \pm 0.048$ & 16.86 & 4.56 & $8.37 \pm 3.65$ & $0.95 \pm 0.153$ & 31.51 & 3.76 \\
\hline CLNP & $1.86 \pm 0.44$ & $0.69 \pm 0.032$ & 23.14 & 12.44 & $2.54 \pm 0.56$ & $1.06 \pm 0.053$ & 35.31 & 13.90 \\
\hline cNP-mNP & $1.40 \pm 0.55$ & $1.35 \pm 0.086$ & 44.85 & 32.03 & $2.13 \pm 0.24$ & $1.77 \pm 0.041$ & 59.07 & 27.73 \\
\hline
\end{tabular}

Reaction conditions: $5 \mathrm{~mL}$ of substrate $\left(2.5\right.$ to $30 \mathrm{mM}$ of PNPP in either solvent), $0.3 \mathrm{~mL}$ of ethanol $(1 \mathrm{M}), 10 \mathrm{mg}$ of each sample (protein), $4 \mu \mathrm{L}$ of water, $30{ }^{\circ} \mathrm{C}, 250 \mathrm{rpm}$ for $5 \mathrm{~min} .200 \mu \mathrm{L}$ of the product was extracted every $1 \mathrm{~min}$, dissolved in $0.1 \mathrm{M} \mathrm{NaOH}$, and detected at $410 \mathrm{~nm}$. The \pm values of $\mathrm{K}_{\mathrm{M}}$ and $\mathrm{V}_{\max }$ are standard deviations calculated by analyzing three individual samples in each case. 
a)

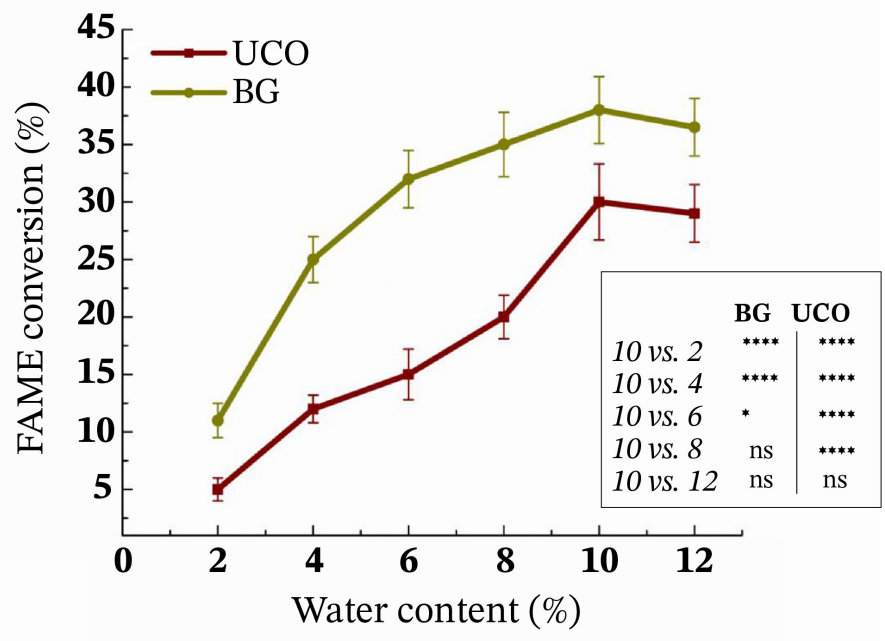

b)

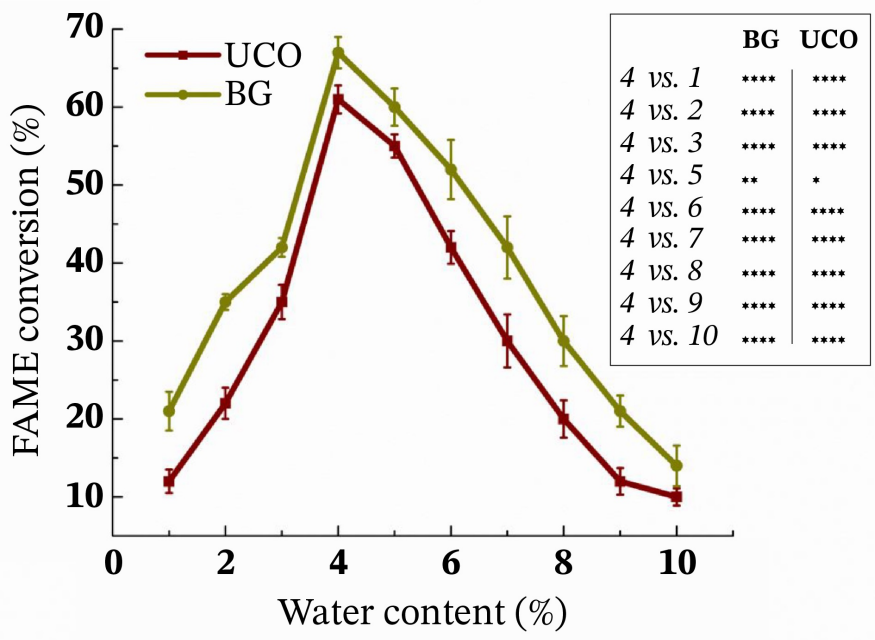

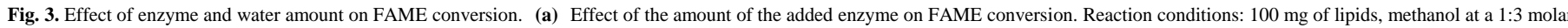

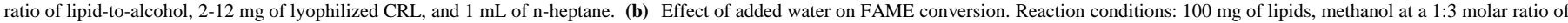

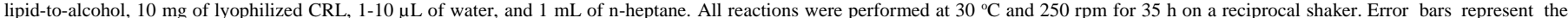

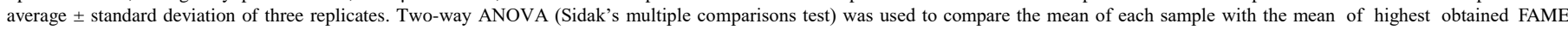
conversion (10\% of enzvme: $4 \%$ of water) and is shown in the insets.

catalytic efficiency $\left(\mathrm{K}_{\mathrm{cat}} / \mathrm{K}_{\mathrm{M}}\right)$ of the samples. Except for CLNP, the catalytic efficiency was overall better in $\mathrm{n}$-heptane. A plethora of factors can cause small differences in enzyme activity in different solvents, including subtle conformational differences, differences in enzyme conformational dynamics, differences in substrate desolvation upon docking to the enzyme, among others (Griebenow and Klibanov, 1996; Zaks and Klibanov, 1988b). Interestingly, previous reports on Candida antarctica lipase B demonstrated higher transesterification activity in 1,4-dioxane at $a_{\mathrm{w}} 0.25$ compared to carbon tetrachloride and toluene (Secundo et al., 2001) while Tasi et al. reported 225 fold activation in esterification reaction performed in chloroform when only 5 $\mu 1 / \mathrm{mL}$ water was added using purified CRL (Tsai and Dordick, 1996).

Importantly it is clearly observable that the NP formulations of the lipase were all vastly superior to the lyophilized powder. It is unclear why the cNP$\mathrm{mNP}$ conjugate performed much better than $\mathrm{cNP}$ and CLNP in the two solvents.

\subsection{Biodiesel production (optimizing conditions)}

The main cost of biodiesel production depends on the feedstock (Canakci and Sanli, 2008). Recycling of otherwise unattractive non-edible feedstock loaded with FFA, like UCO and BG, could significantly reduce costs and are readily available from the fast food industry. While UCO is predominantly available in a liquid form, BG is thick and often semi-solid. Such feedstock can be transformed efficiently only in the soluble form to achieve the desired mass transfer. This could be accomplished by dissolving the viscous substrates in suitable organic solvents, but the lipase must be formulated to work effectively in this context. Fortunately, UCO and BG are readily soluble in n-heptane and 1,4-dioxane and our NP exhibited good activity in these solvents in the model reaction. Apart from $\mathrm{n}$-heptane and 1,4-dioxane, we also employed t-butanol as a solvent because it has been reported to be an excellent solvent for biodiesel synthesis (Royon et al., 2007; Tan et al., 2010) and it allowed us to evaluate the performance of the NP in solvents with a variety of $\log P$ values (Halling, 1990). In the first optimizing step, we performed the biodiesel reaction with both UCO and BG, solubilized in n-heptane, and a variable amount of lyophilized lipase without adding any water to the reaction. The total FAME produced was plotted against the amount of lipase added (Fig. 3a). This experiment gave us an idea on a suitable lipase-to-lipid ratio to produce biodiesel. The FAME conversion was improved with an added amount of CRL up to 10 wt. $\%$. The maximum FAME conversion was $29 \%$ with UCO and $36.5 \%$ with BG. No additional FAME conversion was obtained when enzyme loading was increased further. Therefore, we used this ratio in subsequent experiments. Next, we optimized the water amount in the reaction and for that, $1-10 \mu \mathrm{L}$ water was added, while other parameters kept constant. Similar to the model reaction at $4 \%$ of added water, maximum FAME conversion was achieved in both, UCO and BG (Fig. 3b). The same trend was reported in an earlier work (Tsai and Dordick, 1996) and it is more pronounced with purified CRL than with crude CRL. The decrease of FAME yield after increasing the water amount beyond $4 \%$ might be due to the coalescence of the lipase particles or favoring hydrolysis over transesterification reaction.

Next, we varied the molar ratios of methanol and ethanol at a fixed amount of enzyme and water (Fig. 4a). When BG was used as lipid source, $67 \%$ of FAME and $74 \%$ of FAEE conversion was achieved. No significant effect of methanol on FAME conversion was noticed comparing the 1:3 and 1:4 ratio while no significant effect of ethanol was seen from the 1:2 to 1:5 ratio (Fig. 4a). When the ratio was further increased up to $1: 6$, the FAME/EE conversion was reduced but the effect of ethanol was less pronounced, which agrees with the literature (Lotti et al., 2015). In the case of UCO, data did not show any significant difference from the 1:2 to the 1:4 ratio. However, at the 1:5 ratio, FAME/EE conversion decreased in both, methanol and ethanol, but the effect of ethanol was insubstantial (Fig. $4 \mathrm{~b})$. The highest conversion yield was found when BG and ethanol were used.

\subsection{Time course study of biodiesel production}

A time course study was performed by using BG and methanol in nheptane to understand the catalytic performance of the NP at various time intervals. The performance of cNP-mNP was significantly the best among all tested samples as maximum FAME conversion was achieved (Fig. 5). Except for cNP and CLNP, all samples significantly differed from each other.

\subsection{Biodiesel production in n-heptane, 1,4-dioxane, and t-butanol}

The performance of each sample was analyzed in three solvents, $n$ heptane, 1,4-dioxane, and t-butanol for biodiesel synthesis using BG and UCO as lipid and ethanol or methanol. No effect of the solvent was noticed, which might be due to the fact that a very small amount of water was added to the reactions to serve as molecular lubricant for the enzyme (Fig. 6). A detailed statistical analysis was performed by comparing all possible 

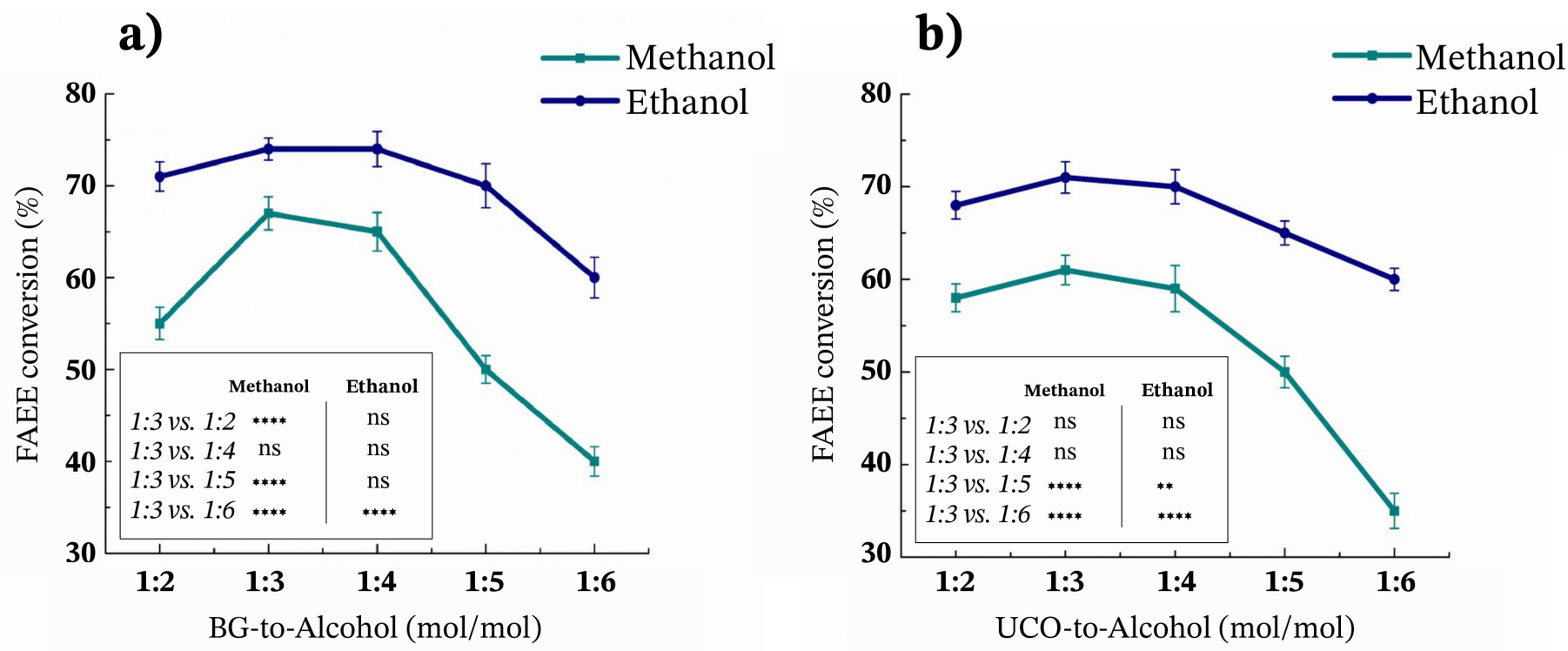

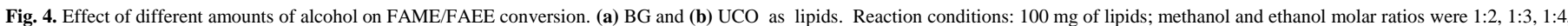

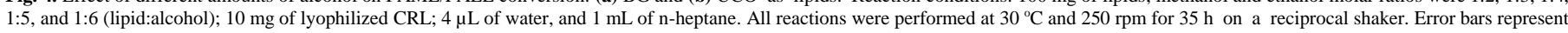

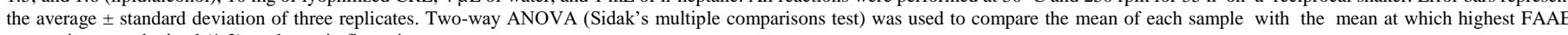
conversion was obtained (1:3) as shown in figure insets.

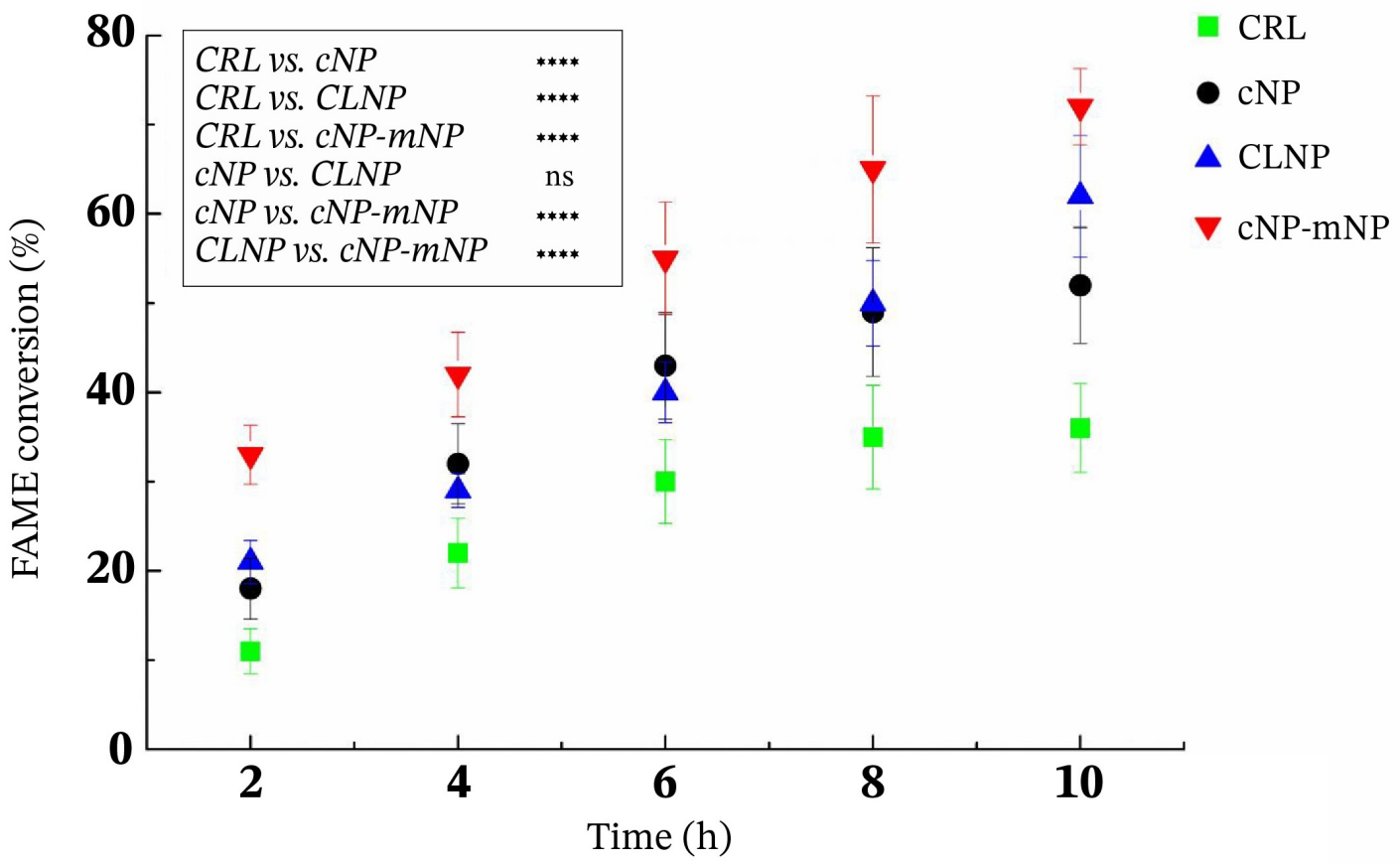

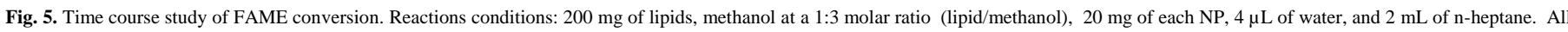

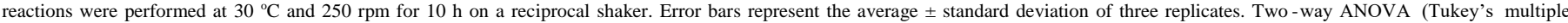
comparisons test) was performed where the FAME conversion \% of all samples were compared with each other (see inset).

combinations of the tested NP and solvents, which yielded some interesting information. It is apparent from Figure 6 that the performance of the NP was increased significantly over lyophilized CRL under all tested conditions. Therefore, first, we focused on the performance of lyophilized CRL only under different substrate conditions. No significant difference was observed. Subsequently, we analyzed the case between lyophilized CRL and NP. A significant difference in performance was found here but some exceptions were also observed (Fig. 7). Most of these exceptions were between CRL and CLNP, which indicates that CLNP was the least effective NP formulation as far as activity is concerned. No difference was observed between $\mathrm{cNP}$ and the cNP-mNP conjugate which is in agreement with expectations since tethering of a NP to another NP should not produce major differences. 
a)

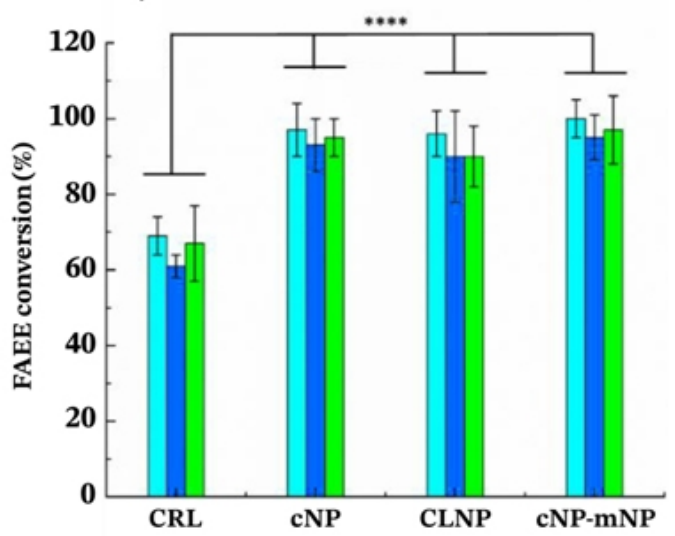

b)

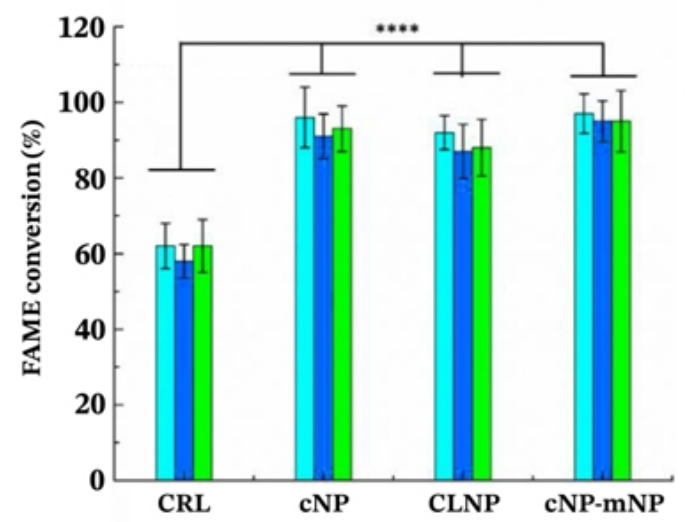

c)

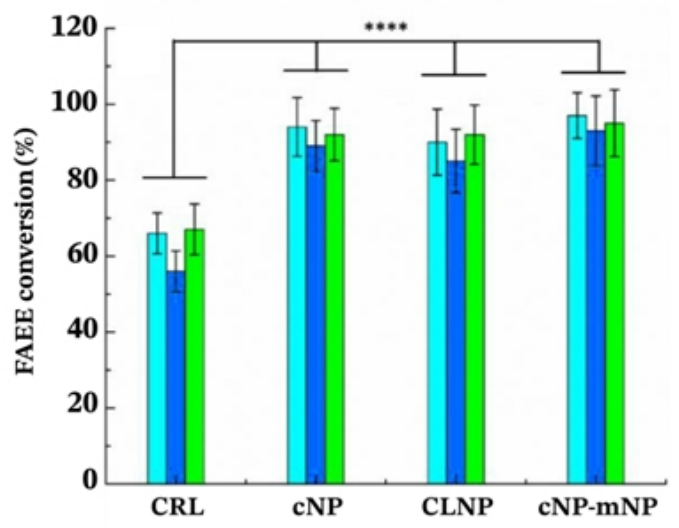

n-heptane

1,4 dioxane

t-butanol

d)

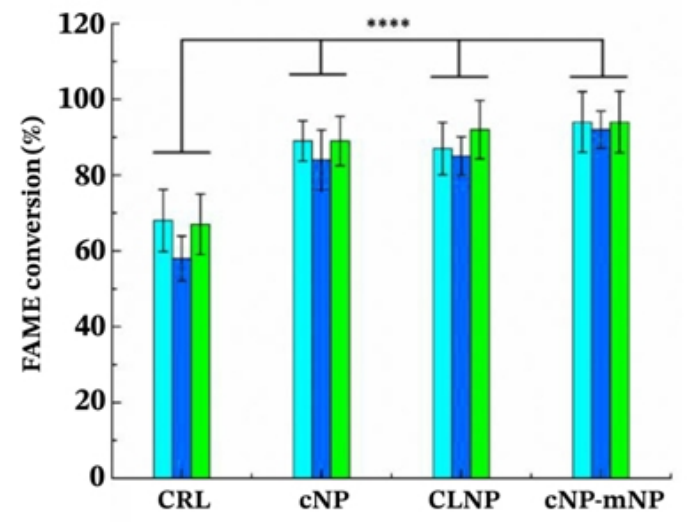

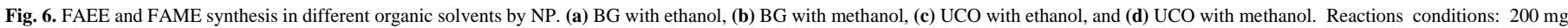

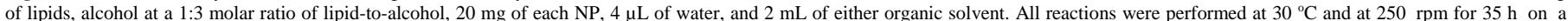

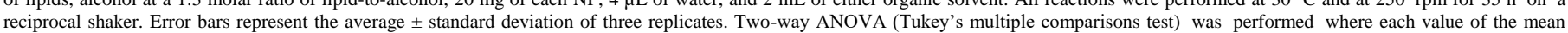

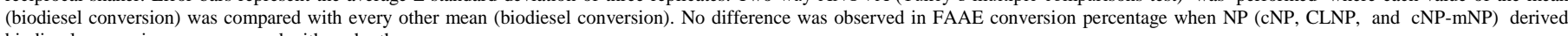
biodiesel conversion was compared with each other.

In the literature, n-heptane or hexane have been reported as the most frequent solvents for biodiesel production because generally lipases work better in non-polar solvents and they improve solubilization of the lipids (Koskinen and Klibanov, 1996). However, 1,4-dioxane and t-butanol have also been used as solvent for biodiesel production (Iso et al., 2001; Royon et al., 2007; Tan et al., 2010). We now find that the choice of solvent is not that relevant and the most economic choice can be chosen when it comes to enzyme activity as long as the water content is adjusted and reaction parameters are optimized and that there is not much influence of the solvent on lipase activity might be related to the structural rigidity of the lipase in organic solvents. For example, when the structure of CRL was studied in water and carbon tetrachloride, no major changes in the structure was observed (Tejo et al., 2004). This is probably the main reason why CRL works efficiently under both, aqueous and nonaqueous conditions, which we have demonstrated in our activity data and also in biodiesel production.

\subsection{Operational and storage stability of the NP}

Operational stability of the catalyst during batch-wise biodiesel production is key to the economy of biodiesel production and therefore, we analyzed it using the four enzyme formulations and BG and ethanol in $\mathrm{n}$-heptane were selected as model reaction (Fig. 7a). In all of the batches, the performance of the NP was superior to that of the lyophilized sample. Lyophilized lipase showed a decrease in activity during each of the five batches studied. No conversion was obtained in the $5^{\text {th }}$ batch using lyophilized CRL. In case of $\mathrm{cNP}$, no difference was found up to the $4^{\text {th }}$ batch but in batch 5 , there was a drop in the activity. When CLNP and cNP-mNP were analyzed, no significant drop in the conversion was found.

These results evidence that our novel formulation strategy was advantageous because we were able to avoid the possible blockage of the enzyme by the deposition of large molecules of lipids and FAAE, which is a common problem in enzyme immobilization (Fjerbaek et al., 2009). We also achieved enhanced thermal stability because nanoparticulate formulation increased the thermal activation compared to the free enzyme as in immobilized form enzyme have more restricted confirmation to overcome the heating effects (Fjerbaek et al., 2009; Verma et al., 2013). Finally, operational stability of the system was also better compared to the literature where after $4^{\text {th }}$ catalytic cycle, drastic drop in the activity was reported (Xie and Ma, 2009). 
a)

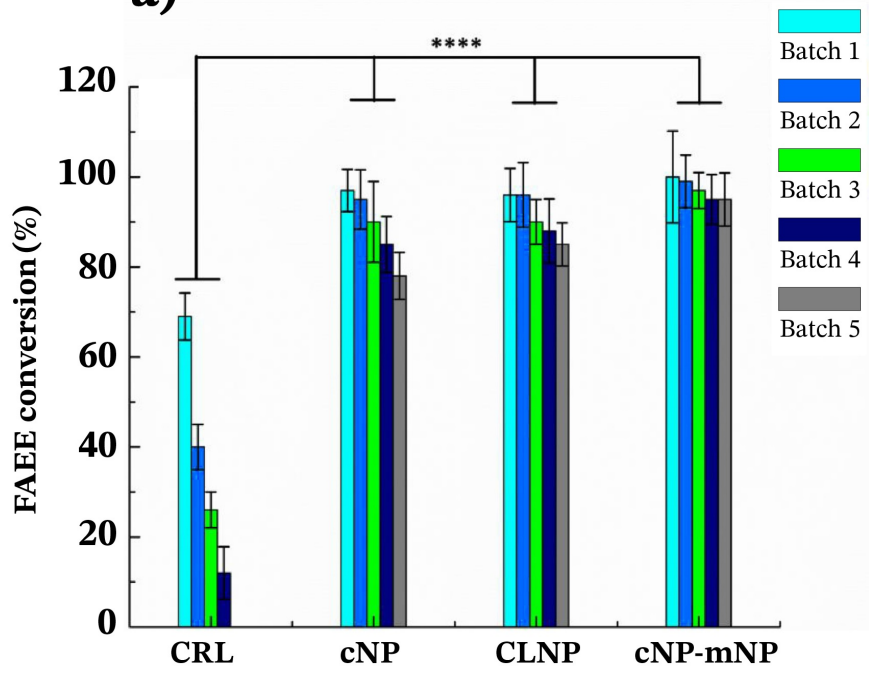

b)

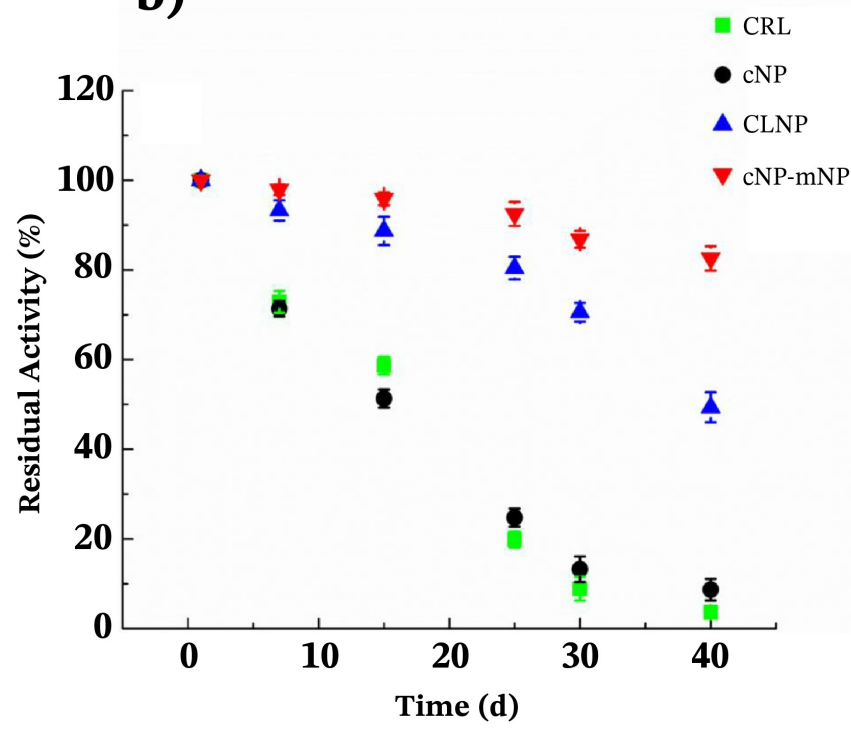

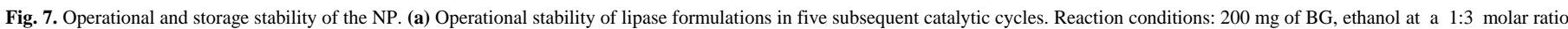

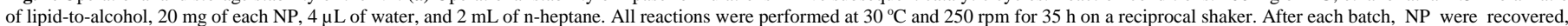

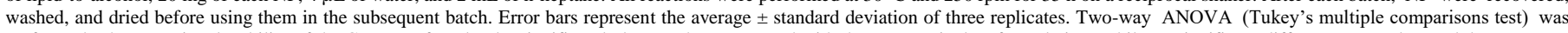

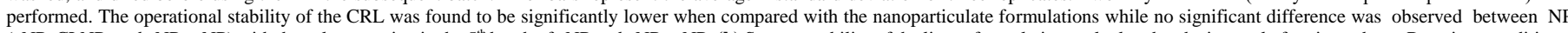

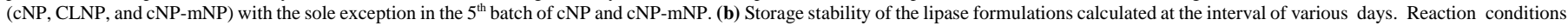

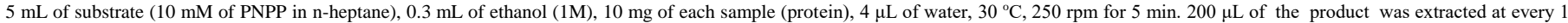

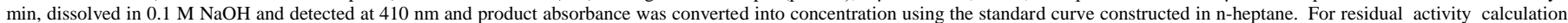

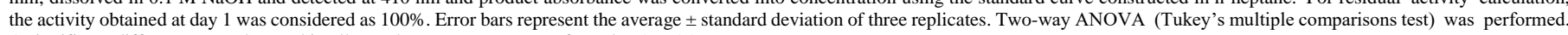
A significant difference was observed in all samples except cNP-mNP from dav 1 to 15 .

Storage stability data of the samples are shown in Figure $7 \mathrm{~b}$. The results signify that crosslinking and conjugation considerably enhanced the storage stability of the lipase NP as nearly 50\% and $82 \%$ activity of CLNP and cNP$\mathrm{mNP}$ were retained even after storing them for $40 \mathrm{~d}$ at $4{ }^{\circ} \mathrm{C}$, respectively. In contrast, no such improvement in the stability of the CRL and cNP were observed. These findings are better than published reports where CRL was immobilized on chitosan beads and retained only $67 \%$ activity in $7 \mathrm{~d}$ of storage (Hung et al., 2003). Statistical analysis revealed that a significant drop in the activity was observed in all samples from day 1 to day 40 . The only exception was cNP-mNP whose activity did not change up to $15 \mathrm{~d}$ and then decreased marginally up to $25 \mathrm{~d}$. These findings along with other experiments suggest that cNP-mNP was the most active and stable formulation in all tested NP.

\section{Conclusions}

In this work, we were able to develop three highly active nano-sized formulations of CRL and performed their detailed characterization. Data of kinetics study showed that conjugated NP (cNP-mNP) were superior among all tested formulations, which is evident from its high $\mathrm{K}_{\text {cat }} / \mathrm{K}_{\mathrm{M}}$ values. The performance of cNP-mNP was superior to the other formulations in the kinetics of biodiesel production and in storage stability experiments. To the best of our knowledge, this is the first study where lipids of the BG apart from UCO were utilized in enzymatic biodiesel production. The high performance of NP is attributed to the inclusion of $\mathrm{M} \beta \mathrm{CD}$ followed by their crosslinking and conjugation, which provided additional activity and stability to the lipase.

\section{References}

[1] Adlercreutz, P., 2013. Immobilisation and application of lipases in organic media. Chem. Soc. Rev. 42(15), 6406-4636.

[2] Benjamin, S., Pandey, A., 1998. Candida rugosa lipases: molecular biology and versatility in biotechnology. Yeast. 14(12), 1069-1087.
[3] Benjamin, S., Pandey, A., 2001. Isolation and characterization of three distinct forms of lipases from Candida rugosa produced in solid state fermentation. Braz. Arch. Biol. Technol. 44(2), 213-221.

[4] Canakci, M., Sanli, H., 2008. Biodiesel production from various feedstocks and their effects on the fuel properties. J. Ind. Microbiol. Biotechnol. 35(5), 431-441.

[5] Cipolatti, E.P., Silva, M.J.A., Klein, M., Feddern, V., Feltes, M.M.C., Oliveira, J.V., Ninow, J.L., de Oliveira, D., 2014. Current status and trends in enzymatic nanoimmobilization. J. Mol. Catal. B: Enzym. 99, 56-67.

[6] De Maria, P., Sanchez-Montero, J.M., Sinisterra, J.V., Alcantara, A.R., 2006. Understanding Candida rugosa lipases: an overview. Biotechnol. Adv. 24(2), 180-196.

[7] Dordick, J.S., 1992. Designing enzymes for use in organic solvents. Biotechnol. Prog. 8(4), 259-267.

[8] Dussan, K.J., Cardona, C.A., Giraldo, O.H., Gutiérrez, L.F., Pérez, V.H., 2010. Analysis of a reactive extraction process for biodiesel production using a lipase immobilized on magnetic nanostructures. Bioresour. Technol. 101(24), 9542-9549.

[9] Dyal, A., Loos, K., Noto, M., Chang, S.W., Spagnoli, C., Shafi, K.V., Ulman, A., Cowman, M., Gross, R.A., 2003. Activity of Candida rugosa lipase immobilized on $\gamma-\mathrm{Fe}_{2} \mathrm{O}_{3}$ magnetic nanoparticles. J. Am. Chem. Soc. 125(7), 1684-1685.

[10] Falony, G., Armas, J.C., Mendoza, J.C.D., Hernández, J.L.M., 2006. Production of extracellular lipase from Aspergillus niger by solid-state fermentation. Food Technol. Biotechnol. 44(2), 235-240.

[11] Fernandez-Lorente, G., Cabrera, Z., Godoy, C., FernandezLafuente, R., Palomo, J.M., Guisan, J. M., 2008. Interfacially activated lipases against hydrophobic supports: effect of the support nature on the biocatalytic properties. Process Biochem. 43(10), 1061-1067. 
[12] Fjerbaek, L., Christensen, K.V., Norddahl, B., 2009. A review of the current state of biodiesel production using enzymatic transesterification. Biotechnol. Bioenergy. 102(5), 1298-1315.

[13] Griebenow, K., Klibanov, A.M., 1996. On protein denaturation in aqueous-organic mixtures but not in pure organic solvents. J. Am. Chem. Soc. 118(47), 11695-11700.

[14] Griebenow, K., Laureano, Y.D., Santos, A.M., Clemente, I.M., Rodríguez, L., Vidal, M.W., Barletta, G., 1999. Improved enzyme activity and enantioselectivity in organic solvents by methyl- $\beta$ cyclodextrin. J. Am. Chem. Soc. 121(36), 8157-8163.

[15] Grochulski, P., Li, Y., Schrag, J.D., Cygler, M., 1994. Two conformational states of Candida rugosa lipase. Protein Sci. 3(1), 8291.

[16] Halling, P.J., 1990. Solvent selection for biocatalysis in mainly organic systems: predictions of effects on equilibrium position. Biotechnol. Bioenergy. 35(7), 691-701

[17] Hirata, H., Higuchi, K., Yamashina, T., 1990. Lipase-catalyzed transesterification in organic solvent: effects of water and solvent, thermal stability and some applications. J. Biotechnol. 14(2), 157-167.

[18] Hung, T.C., Giridhar, R., Chiou, S.H., Wu, W.T., 2003. Binary immobilization of Candida rugosa lipase on chitosan. J. Mol. Catal. B: Enzym. 26(1-2), 69-78

[19] Iso, M., Chen, B., Eguchi, M., Kudo, T., Shrestha, S., 2001. Production of biodiesel fuel from triglycerides and alcohol using immobilized lipase. J. Mol. Catal. B: Enzym. 16(1), 53-58.

[20] Kamat, S., Beckman, E.J., Russell, A.J., 1992. Role of diffusion in nonaqueous enzymology. 1. theory. Enzyme Microb. Technol. 14(4), 265-271.

[21] Kartal, F., Janssen, M.H., Hollmann, F., Sheldon, R.A., Kılınc, A., 2011. Improved esterification activity of Candida rugosa lipase in organic solvent by immobilization as cross-linked enzyme aggregates (CLEAs). J. Mol. Catal. B: Enzym. 71(3-4), 85-89.

[22] Kim, B.H., Lee, N., Kim, H., An, K., Park, Y.I., Choi, Y., Shin, K., Lee, Y., Kwon, S.G., Na, H.B., 2011. Large-scale synthesis of uniform and extremely small-sized iron oxide nanoparticles for high-resolution $T_{l}$ magnetic resonance imaging contrast agents. J. Am. Chem. Soc. $133(32), 12624-12631$

[23] Kim, J., Grate, J.W., Wang, P., 2008. Nanobiocatalysis and its potential applications. Trends Biotechnol. 26(11), 639-646.

[24] Klibanov, A.M., 2001. Improving enzymes by using them in organic solvents. Nature. 409(6817), 241

[25] Kojima, S., Du, D., Sato, M., Park, E.Y., 2004. Efficient production of fatty acid methyl ester from waste activated bleaching earth using diesel oil as organic solvent. J. Biosci. Bioenergy. 98(6), 420-424.

[26] Koskinen, A.M., Klibanov, A. M., 1996. Enzymatic reactions in organic media. Springer, New York, Chapman and Hall. 1-319.

[27] Kuo, C.H., Peng, L.T., Kan, S.C., Liu, Y.C., Shieh, C.J., 2013. Lipaseimmobilized biocatalytic membranes for biodiesel production. Bioresour. Technol. 145, 229-232

[28] Kuo, T.C., Shaw, J.F., Lee, G.C., 2015. Conversion of crude Jatropha curcas seed oil into biodiesel using liquid recombinant Candida rugosa lipase isozymes. Bioresour. Technol. 192, 54-59.

[29] Langer, K., Balthasar, S., Vogel, V., Dinauer, N., von Briesen, H., Schubert, D., 2003. Optimization of the preparation process for human serum albumin (HSA) nanoparticles. Int. J. Pharm. 257(1-2), 169-180.

[30] Li, X., Zhu, H., Feng, J., Zhang, J., Deng, X., Zhou, B., Zhang, H., Xue, D., Li, F., Mellors, N. J., 2013. One-pot polylol synthesis of graphene decorated with size-and density-tunable $\mathrm{Fe}_{3} \mathrm{O}_{4}$ nanoparticles for porcine pancreatic lipase immobilization. Carbon 60, 488-497.

[31] Linko, Y.Y., Lämsä, M., Huhtala, A., Rantanen, O., 1995. Lipase biocatalysis in the production of esters. J. Am. Oil Chem. Soc. 72(11), 1293-1299.

[32] Liou, Y.C., Marangoni, A.G., Yada, R.Y., 1998. Aggregation behavior of Candida rugosa lipase. Food Res. Int. 31(3), 243-248.

[33] Lotti, M., Pleiss, J., Valero, F., Ferrer, P., 2015. Effects of methanol on lipases: molecular, kinetic and process issues in the production of biodiesel. Biotechnol. J. 10(1), 22-30.

[34] Mahdavi, M., Ahmad, M.B., Haron, M.J., Namvar, F., Nadi, B., Rahman, M.Z.A., Amin, J., 2013. Synthesis, surface modification and characterisation of biocompatible magnetic iron oxide nanoparticles for biomedical applications. Molecules. 18(7), 7533-7548.

[35] Mahmoudi, M., Sant, S., Wang, B., Laurent, S., Sen, T., 2011. Superparamagnetic iron oxide nanoparticles (SPIONs) development, surface modification and applications in chemotherapy. Adv. Drug Delivery Rev. 63(1-2), 24-46.

[36] Mei, Y., Miller, L., Gao, W., Gross, R.A., 2003. Imaging the distribution and secondary structure of immobilized enzymes using infrared microspectroscopy. Biomacromolecules. 4(1), 70-74.

[37] Montalvo, B.L., Pacheco, Y., Sosa, B.A., Vélez, D., Sánchez, G., Griebenow, K., 2008. Formation of spherical protein nanoparticles without impacting protein integrity. Nanotechnology. 19(46), 465103 .

[38] Montero, S., Blanco, A., Virto, M.D., Landeta, L.C., Agud, I., Solozabal, R., Lascaray, J., de Renobales, M., Llama, M. J., Serra, J.L., 1993. Immobilization of Candida rugosa lipase and some properties of the immobilized enzyme. Enzyme Microb. Technol. 15(3), 239-247

[39] Parida, S., Dordick, J.S., 1993. Tailoring lipase specificity by solvent and substrate chemistries. J. Org. Chem. 58(12), 3238-3244

[40] Park, E.Y., Sato, M., Kojima, S., 2008. Lipase-catalyzed biodiese production from waste activated bleaching earth as raw material in a pilot plant. Bioresour. Technol. 99(8), 3130-3135.

[41] Pinsirodom, P., Parkin, K.L., 2001. Lipase assays. Current protocols in food analytical chemistry. 1, C3-1.

[42] Rebelo, L.P., Netto, C.G., Toma, H.E., Andrade, L.H., 2010 Enzymatic kinetic resolution of (RS)-1-(Phenyl) ethanols by Burkholderia cepacia lipase immobilized on magnetic nanoparticles. J. Braz. Chem. Soc. 21(8), 1537-1542.

[43] Ribeiro, B.D., de Castro, A.M., Coelho, M.A.Z., Freire, D.M.G. 2011. Production and use of lipases in bioenergy: a review from the feedstocks to biodiesel production. Enzyme Res. 2011, 1-16.

[44] Royon, D., Daz, M., Ellenrieder, G., Locatelli, S., 2007. Enzymatic production of biodiesel from cotton seed oil using $t$-butanol as a solvent. Bioresour. Technol. 98(3), 648-653.

[45] Rúa, M.L., Ballesteros, A., 1994. Rapid purification of two lipase isoenzymes from Candida rugosa. Biotechnol. Technol. 8(1), 21 26

[46] Schenk, P.M., Thomas-Hall, S.R., Stephens, E., Marx, U.C. Mussgnug, J.H., Posten, C., Kruse, O., Hankamer, B., 2008. Second generation biofuels: high-efficiency microalgae for biodiesel production. Bioenergy Res. 1(1), 20-43.

[47] Schober, S., Seidl, I., Mittelbach, M., 2006. Ester content evaluation in biodiesel from animal fats and lauric oils. Eur. J. Lipid Sci. Techol. 108(4), 309-314

[48] Secundo, F., Carrea, G., Soregaroli, C., Varinelli, D., Morrone, R. 2001. Activity of different Candida antarctica lipase B formulations in organic solvents. Biotechnol. Bioenergy. 73(2), 157-163

[49] Shah, S., Sharma, S., Gupta, M., 2004. Biodiesel preparation by lipase-catalyzed transesterification of Jatropha oil. Energy Fuels 18(1), 154-159.

[50] Shao, P., Meng, X., He, J., Sun, P., 2008. Analysis of immobilized Candida rugosa lipase catalyzed preparation of biodiesel from rapeseed soapstock. Food Bioprod. Process. 86(4), 283-289.

[51] Sharma, R.K., Saxena, M., O’Neill, C.A., Ramos, H.A., Griebenow, K., 2018. Synthesis of Rhizopus arrhizus lipase nanoparticles for biodiesel production. ACS Omega. 3(12), 18203-18213

[52] Sheldon, R.A., Schoevaart, R., Van Langen, L.M., 2005. Crosslinked enzyme aggregates (CLEAs): a novel and versatile method for enzyme immobilization (a review). Biocatal. Biotransform. 23(3-4), 141-147.

[53] Sheldon, R.A., 2010. Cross-linked enzyme aggregates as industria biocatalysts. Org. Process Res. Dev. 15(1), 213-223

[54] Solanki, K., Gupta, M.N., 2011. Simultaneous purification and immobilization of Candida rugosa lipase on superparamagnetic $\mathrm{Fe}_{3} \mathrm{O}_{4}$ nanoparticles for catalyzing transesterification reactions. New J. Chem. 35(11), 2551 
[55] Talebi, A.F., Tabatabaei, M., Chisti, Y., 2014. BiodieselAnalyzer: a user-friendly software for predicting the properties of prospective biodiesel. Biofuel Res. J. 1(2), 55-57.

[56] Tan, T., Lu, J., Nie, K., Deng, L., Wang, F., 2010. Biodiesel production with immobilized lipase: a review. Biotechnol. Adv. 28(5), 628-634.

[57] Tejo, B.A., Salleh, A.B., Pleiss, J., 2004. Structure and dynamics of Candida rugosa lipase: the role of organic solvent. J. Mol. Model. 10(56), 358-366.

[58] Thapa, B., Diaz-Diestra, D., Beltran-Huarac, J., Weiner, B.R., Morell, G., 2017. Enhanced MRI T 2 relaxivity in contrast-probed anchor-free PEGylated iron oxide nanoparticles. Nanoscale Res. Lett. 12(1), 312.

[59] Thapa, B., Diaz-Diestra, D., Santiago-Medina, C., Kumar, N., Tu, K., Beltran-Huarac, J., Jadwisienczak, W.M., Weiner, B.R., Morell, G., 2018. $\mathrm{T}_{1}$-and $\mathrm{T}_{2}$-weighted magnetic resonance dual contrast by single core truncated cubic iron oxide nanoparticles with abrupt cellular internalization and immune evasion. ACS Appl. Bio Mater. 1(1), 7989.

[60] Thapa, B., Diaz-Diestra, D., Badillo-Diaz, D., Sharma, R.K., Dasari, K., Kumari, S., Holcomb, M.B., Beltran-Huarac, J., Weiner, B.R., Morell, G., 2019. Controlling the transverse proton relaxivity of magnetic graphene oxide. Sci. Rep. 9, 5633

[61] Tsai, S.W., Dordick, J.S., 1996. Extraordinary enantiospecificity of lipase catalysis in organic media induced by purification and catalyst engineering. Biotechnol. Bioengy. 52(2), 296-300.

[62] Verma, M.L., Barrow, C.J., Puri, M., 2013. Nanobiotechnology as a novel paradigm for enzyme immobilisation and stabilisation with potential applications in biodiesel production. Appl. Microbiol. Biotechnol. 97(1), 23-39.

[63] Wang, X., Dou, P., Zhao, P., Zhao, C., Ding, Y., Xu, P., 2009. Immobilization of lipases onto magnetic $\mathrm{Fe}_{3} \mathrm{O}_{4}$ nanoparticles for application in biodiesel production. ChemSusChem. Sustainability Energy Mat. 2(10), 947-950.
[64] Wang, H., Yao, Q., Wang, C., Fan, B., Sun, Q., Jin, C., Xiong, Y. Chen, Y., 2016. A simple, one-step hydrothermal approach to durable and robust superparamagnetic, superhydrophobic and electromagnetic wave-absorbing wood. Sci. Rep. 6, 35549.

[65] Wang, J., Meng, G., Tao, K., Feng, M., Zhao, X., Li, Z., Xu, H. Xia, D., Lu, J.R., 2012. Immobilization of lipases on alkyl silane modified magnetic nanoparticles: effect of alkyl chain length on enzyme activity. PloS one. 7(8), e43478.

[66] Xie, W., Ma, N., 2009. Immobilized lipase on $\mathrm{Fe}_{3} \mathrm{O}_{4}$ nanoparticles as biocatalyst for biodiesel production. Energy Fuels. 23, $1347-$ 1353.

[67] Xu, J.K., Zhang, F.F., Sun, J.J., Sheng, J., Wang, F., Sun, M., 2014 Bio and nanomaterials based on $\mathrm{Fe}_{3} \mathrm{O}_{4}$. Molecules. 19(12), 21506 21528.

[68] Xun, E.N., Lv, X.1., Kang, W., Wang, J.X., Zhang, H., Wang, L., Wang, Z., 2012. Immobilization of Pseudomonas fluorescens lipase onto magnetic nanoparticles for resolution of 2-octanol. Appl. Biochem. Biotechnol. 168(3), 697-707.

[69] Yong, Y., Bai, Y.X., Li, Y.F., Lin, L., Cui, Y.J., Xia, C.G., 2008. Characterization of Candida rugosa lipase immobilized onto magnetic microspheres with hydrophilicity. Process Biochem. 43(11), 1179-1185.

[70] Yu, C.Y., Huang, L.Y., Kuan, I., Lee, S.L., 2013. Optimized production of biodiesel from waste cooking oil by lipase immobilized on magnetic nanoparticles. Int. J. Mol. Sci. 14, 24074 24086.

[71] Yu, H., Chen, H., Wang, X., Yang, Y., Ching, C., 2006. Crosslinked enzyme aggregates (CLEAs) with controlled particles: application to Candida rugosa lipase. J. Mol. Catal. B: Enzym. 43, 124-127.

[72] Zaks, A., Klibanov, A.M., 1988a. The effect of water on enzyme action in organic media. J. Biol. Chem. 263, 8017-8021.

[73] Zaks, A., Klibanov, A.M., 1988b. Enzymatic catalysis in nonaqueous solvents. J. Biol. Chem. 263, 3194-3201. 


\section{Supplementary file}

Table S1.

Purification of crude CRL.

\begin{tabular}{lcccc}
\hline Purification step & $\begin{array}{c}\text { Total protein } \\
(\mathbf{m g})\end{array}$ & $\begin{array}{c}\text { Specific activity } \\
(\mathbf{U} / \mathbf{m g})\end{array}$ & $\begin{array}{c}\text { Purification } \\
(\mathbf{f o l d})\end{array}$ & $\begin{array}{c}\text { Yield } \\
(\%)\end{array}$ \\
\hline Crude & 2250 & 140 & 1.00 & 100 \\
$\begin{array}{l}\text { Spin }(17,000 \text { g), ethanol } \\
\text { precipitate, and dialysis }\end{array}$ & 1575 & 579 & 4.13 & 75 \\
$\begin{array}{l}\text { Phenyl-sepharose } \\
\begin{array}{l}\text { Amicon Ultra- } \\
\text { Centrifugal Filter Units }\end{array}\end{array}$ & 529 & 890 & 6.35 & 29 \\
$\begin{array}{l}\text { Gel filtration } \\
\text { a Activity measured by olive oil titration method. }\end{array}$ & 1126 & 8.04 & 15 \\
\end{tabular}

${ }^{\text {a }}$ Activity measured by olive oil titration method.

\section{a)}

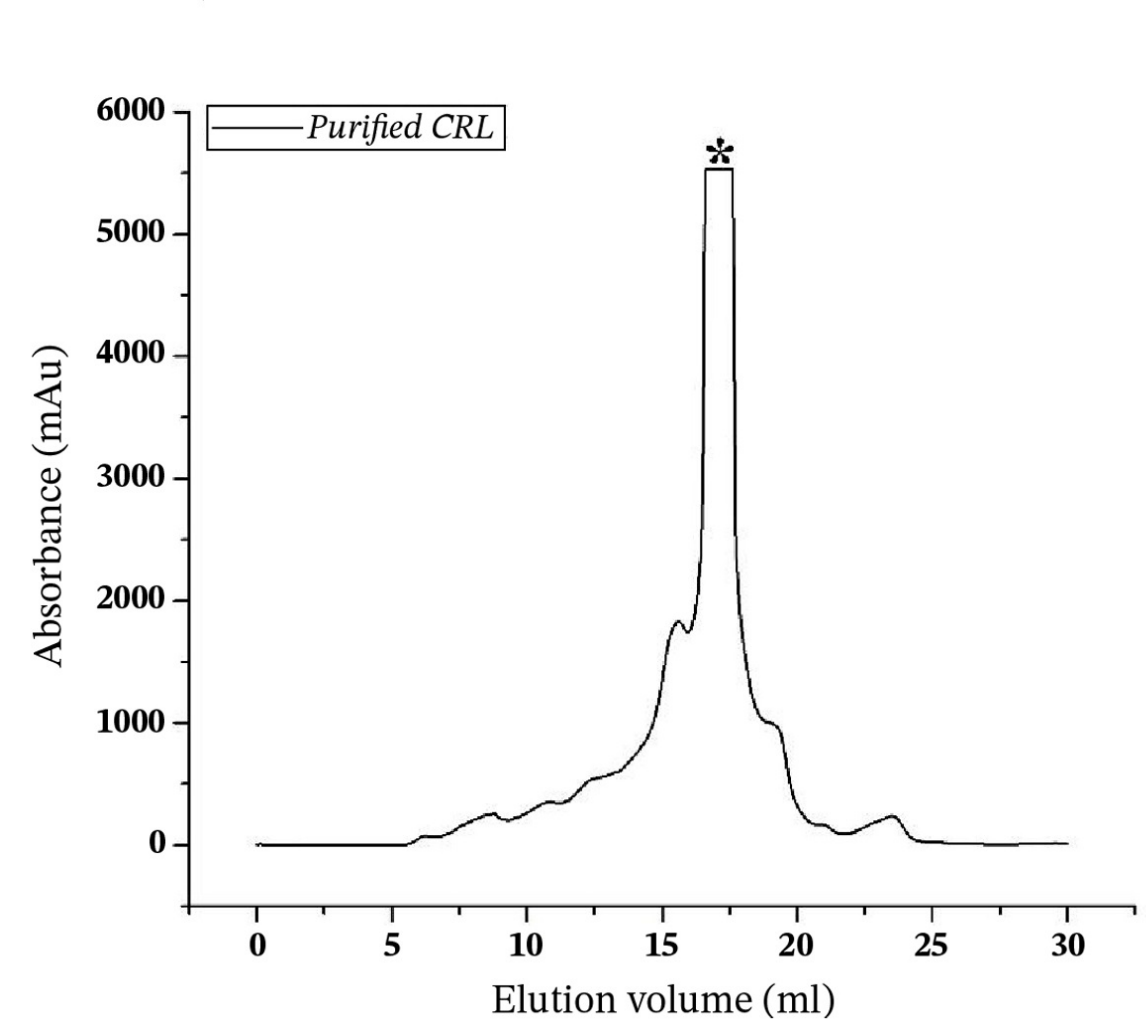

\section{b)}

$1718 \quad$ Marker

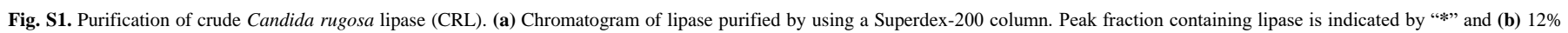
SDS-PAGE gradient gel showing the peak fractions 17 and 18 obtained from Superdex-200 purification and their estimated $\mathrm{M}_{\mathrm{w}}$ by using Novex ${ }^{\mathrm{TM}}$ Sharp Pre-stained Protein Standard. 
a)

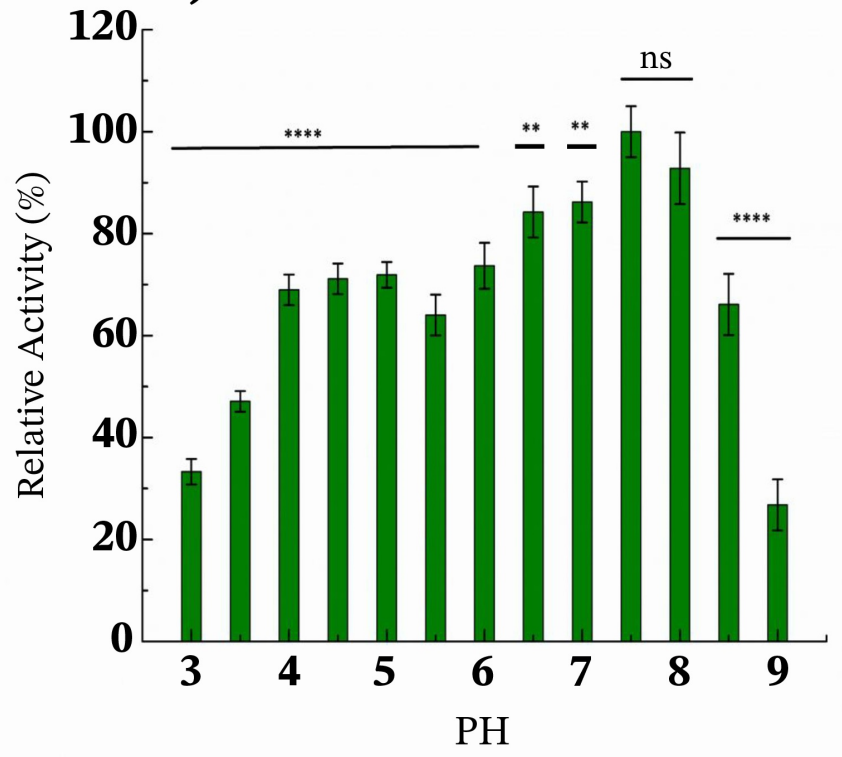

b)

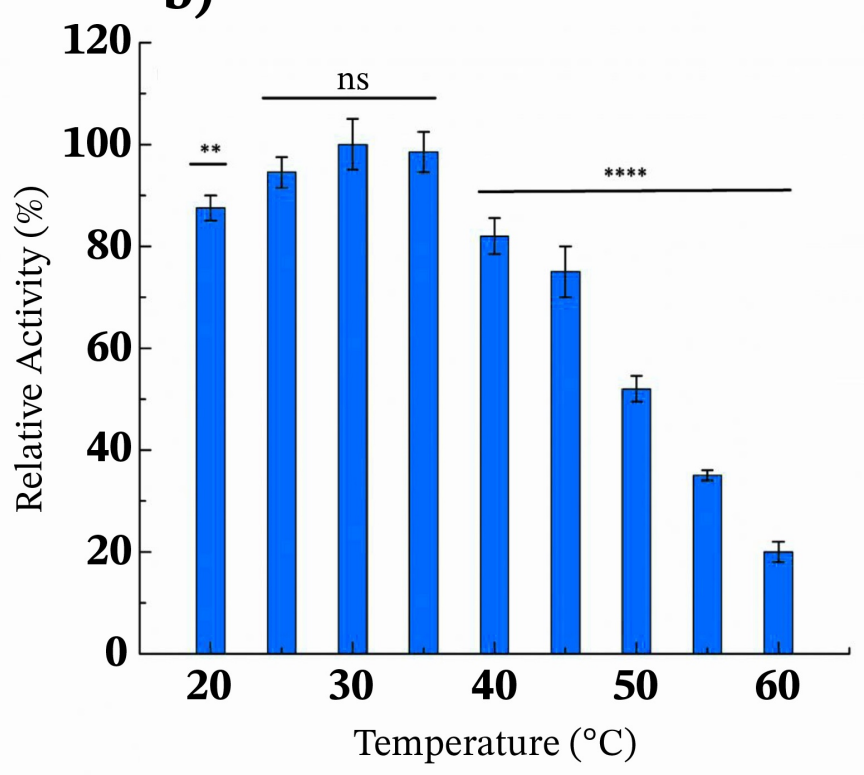

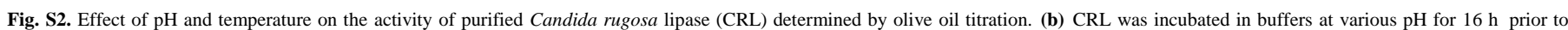

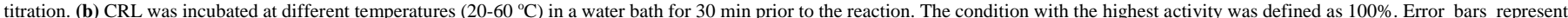

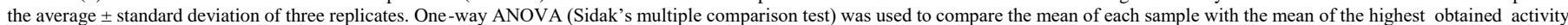
$\left(\mathrm{pH} 7.5 ; 30^{\circ} \mathrm{C}\right)$

Table S2.

Nanoprecipitation results at various CRL concentrations at a 1:4 volume ratio of buffer-to-solvents (THF and dioxane).

\begin{tabular}{|c|c|c|c|c|c|c|}
\hline \multirow{2}{*}{$\begin{array}{l}\text { CRL concentration } \\
(\mathrm{mg} / \mathrm{mL})\end{array}$} & \multicolumn{2}{|c|}{ NP yield (\%) } & \multicolumn{2}{|c|}{ Residual activity (\%) } & \multicolumn{2}{|c|}{ Radius (nm) } \\
\hline & THF & 1,4-dioxane & THF & 1,4-dioxane & THF & 1,4-dioxane \\
\hline 2 & $87 \pm 5$ & $88 \pm 9$ & $91 \pm 10$ & $88 \pm 1$ & $100 \pm 15$ & $90 \pm 10$ \\
\hline 4 & $95 \pm 8$ & $98 \pm 5$ & $100 \pm 5$ & $100 \pm 7$ & $130 \pm 10$ & $120 \pm 5$ \\
\hline 6 & $95 \pm 6$ & $98 \pm 8$ & $100 \pm 7$ & $100 \pm 9$ & $145 \pm 20$ & $135 \pm 8$ \\
\hline 8 & $82 \pm 2$ & $91 \pm 5$ & $97 \pm 0$ & $98 \pm 10$ & $160 \pm 15$ & $140 \pm 15$ \\
\hline 10 & $75 \pm 5$ & $85 \pm 3$ & $95 \pm 4$ & $96 \pm 5$ & $175 \pm 20$ & $175 \pm 12$ \\
\hline 20 & $70 \pm 8$ & $75 \pm 9$ & $82 \pm 5$ & $85 \pm 3$ & $185 \pm 10$ & $190 \pm 10$ \\
\hline
\end{tabular}

The \pm values are standard deviations calculated by analyzing three individual samples in each case. 
Table S3.

Effect of solvent (1,4-dioxane) addition rate on precipitation yield, activity, and polydispersity index.

\begin{tabular}{lcc}
\hline Solvent addition rate $(\mathbf{m L} / \mathbf{h})$ & Residual activity $(\%)$ & Polydispersity index (PDI) \\
80 & $98 \pm 7$ & - \\
100 & $98 \pm 2$ & $0.7 \pm 0.02$ \\
120 & $100 \pm 8$ & $0.2 \pm 0.01$ \\
140 & $99 \pm 5$ & $0.26 \pm 0.02$ \\
160 & $95 \pm 2$ & $0.27 \pm 0.02$ \\
180 & $95 \pm 1$ & $0.3 \pm 0.025$ \\
200 & $88 \pm 5$ & $0.35 \pm 0.021$ \\
\hline
\end{tabular}

The \pm values are standard deviations calculated by analyzing three individual samples in each case.
Table S4.

Effect of crosslinking time and reaction temperature on activity of the CLNP. CRL-toglutaraldehyde ratio was 1:200 (mol:mol) under all conditions.

\begin{tabular}{lcc}
\hline Crosslinking time (min) & Temperature $\left({ }^{\circ} \mathbf{C}\right)$ & Relative activity $(\%)$ \\
\hline 60 & RT & $95 \pm 2$ \\
60 & 4 & $78 \pm 9$ \\
600 & 4 & $98 \pm 5$ \\
960 & 4 & $100 \pm 1$ \\
15 & 37 & $96+3$ \\
\hline
\end{tabular}

The \pm values are standard deviations calculated by analyzing three individual samples in each case.
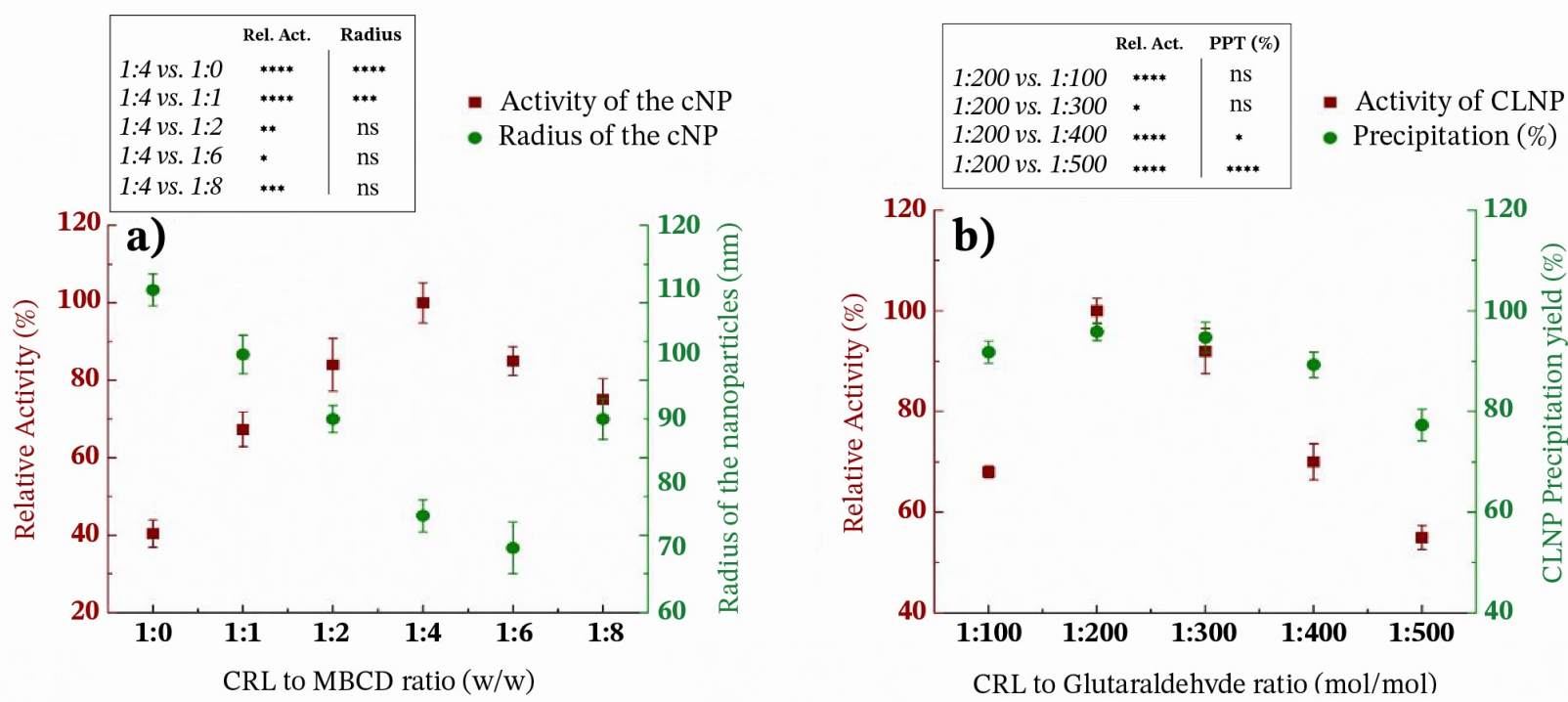

CRL to Glutaraldehvde ratio $(\mathrm{mol} / \mathrm{mol})$

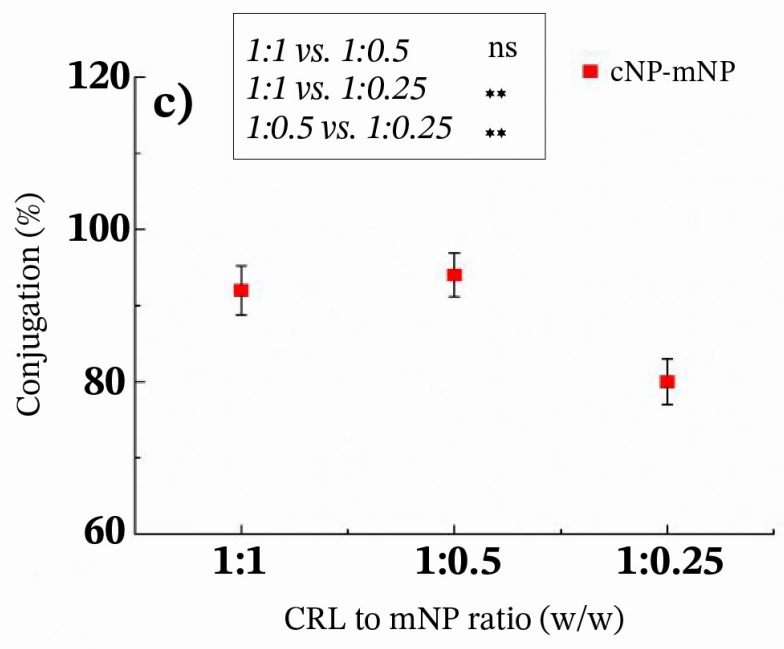

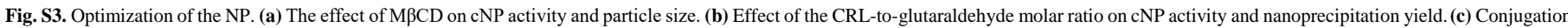

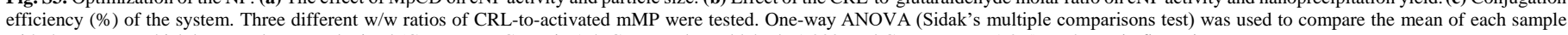
with the mean at which best results were obtained (CRL-to-MBCD ratio 1:4, CRL-to-glutaraldehyde 1:200, and CRL-to-mNP 1:0.5) as shown in figure insets.

Please cite this article as: Sharma R.K., O'Neill C.A., Ramos H.A.R., Thapa B., Barcelo-Bovea V.C., Gaur K., Griebenow K. Candida rugosa lipase nanoparticles as robust catalyst for biodiesel production in organic solvents. Biofuel Research Journal 23 (2019) 1025-1038. DOI: 10.18331/BRJ2019.6.3.3 
Table S5.

Data obtained by DLS for the different NP.

\begin{tabular}{cccc}
\hline Sample & Radius (nm) & $\begin{array}{c}\text { Polydispersity index } \\
(\text { PDI) }\end{array}$ & $\begin{array}{c}\text { Zeta potential } \\
(\mathbf{m V})\end{array}$ \\
\hline cNP & $75 \pm 5$ & $0.10 \pm 0.0015$ & -16 \\
CLNP & $100 \pm 10$ & $0.65 \pm 0.02$ & -25 \\
cNP-mNP Conjugate & $85 \pm 5$ & $0.22 \pm 0.019$ & -20 \\
\hline
\end{tabular}

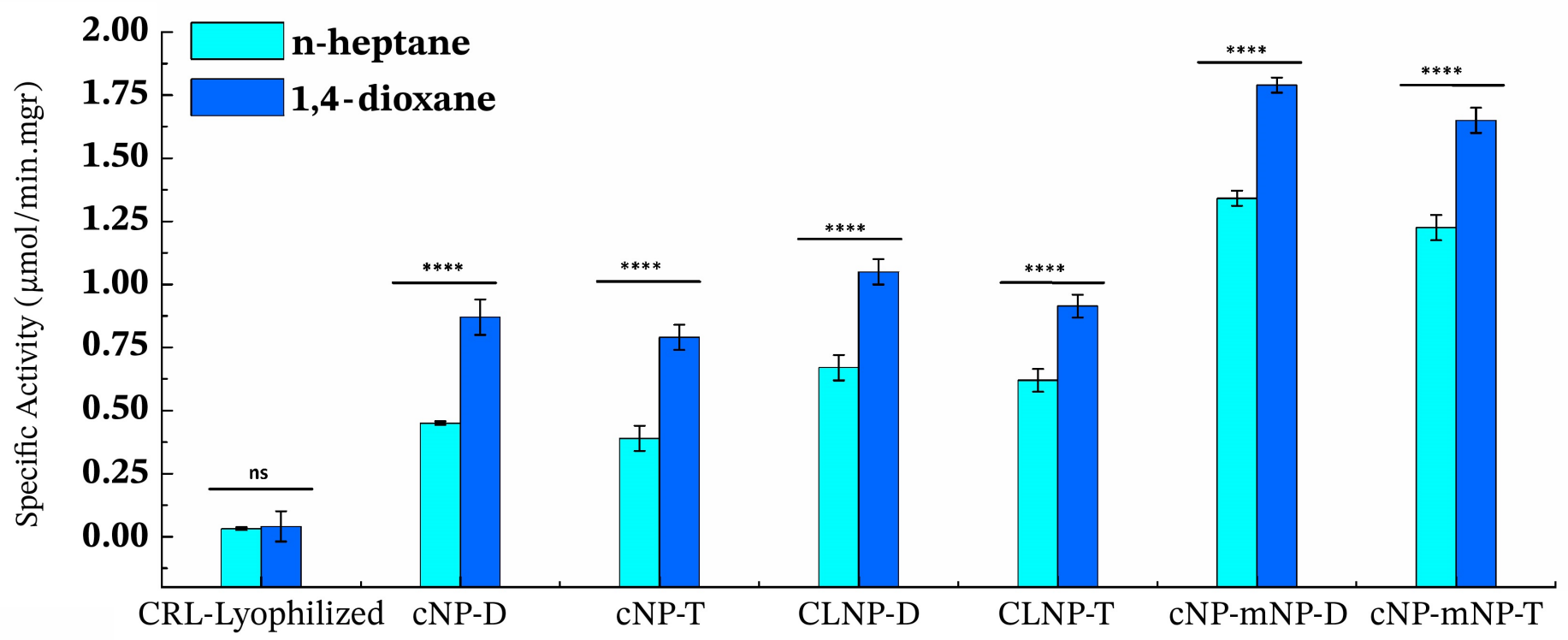

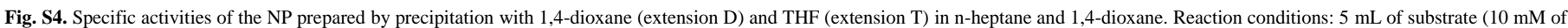

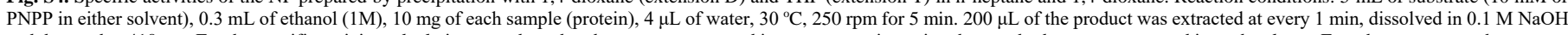

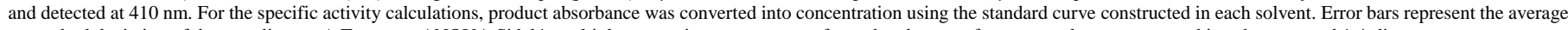
\pm standard deviation of three replicates. A Two-way ANOVA Sidak's multiple comparisons test was performed and mean of same sample was compared in n-heptane and 1,4-dioxane. 

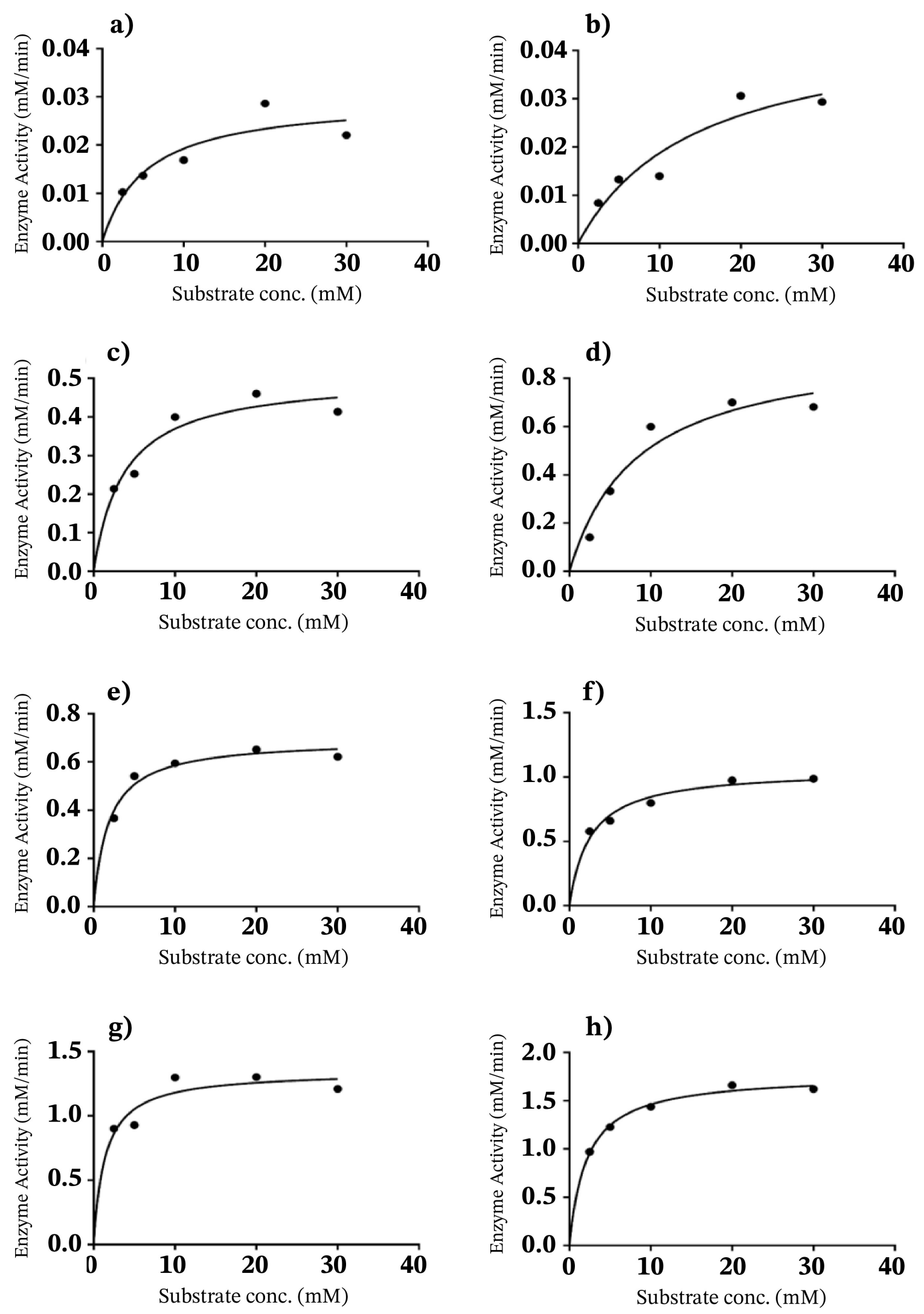

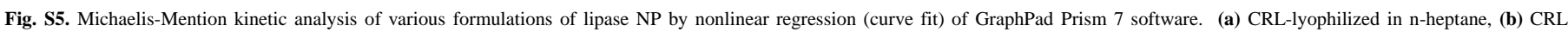
lyophilized in dioxane, (c) cNP in n-heptane, (d) cNP in 1,4-dioxane, (e) CLNP in n-heptane, (f) CLNP in 1,4-dioxane, (g) cNP-mNP in n-heptane, and (h) cNP-mNP in 1,4-dioxane. 
a)

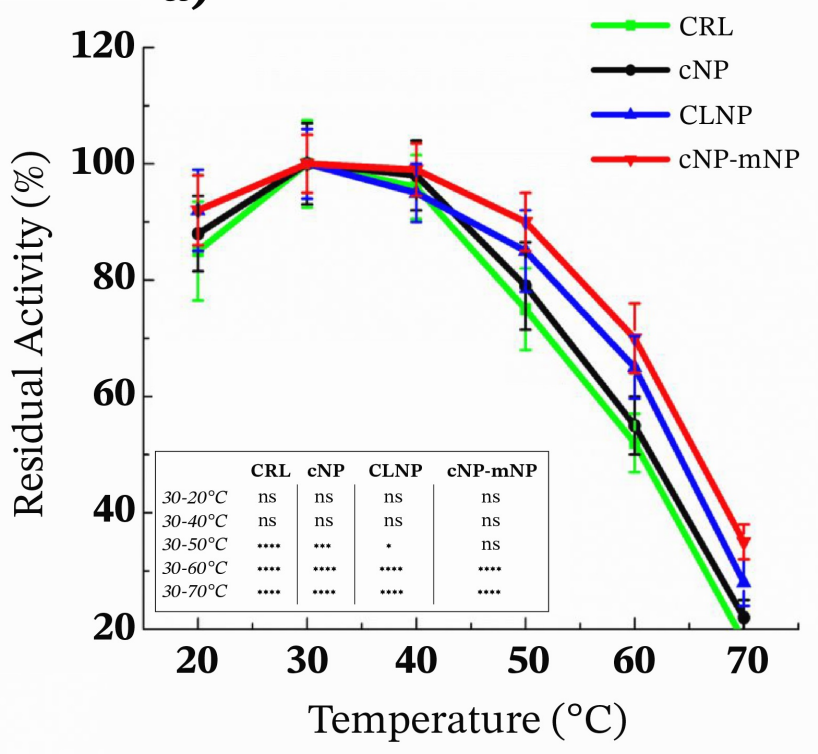

b)

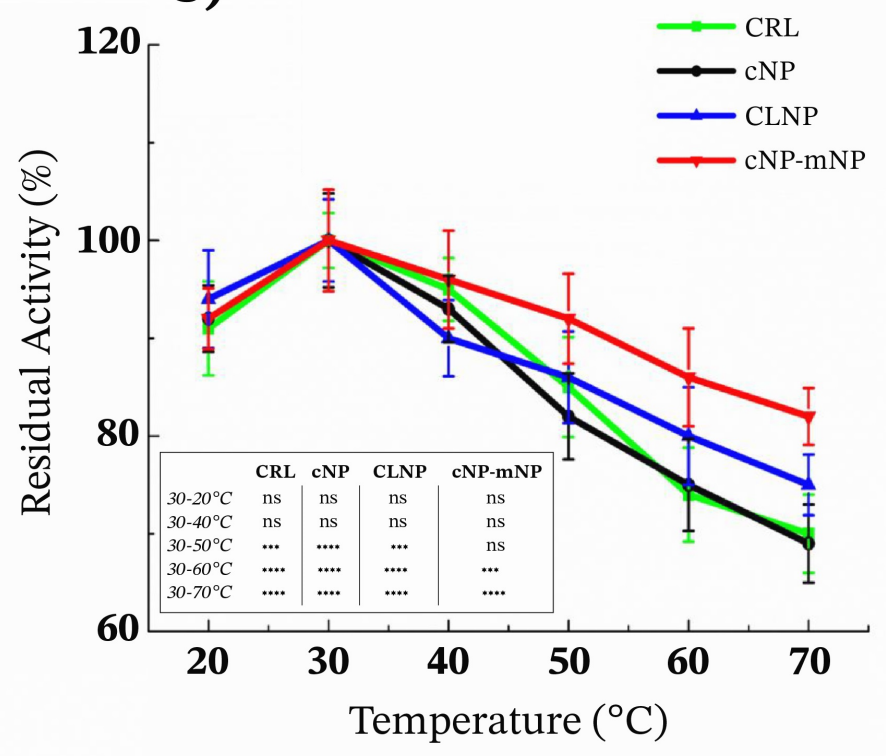

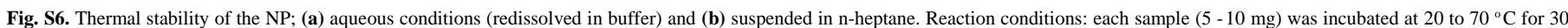

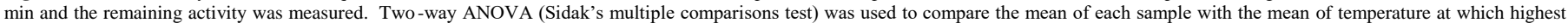
residual activity was obtained $\left(30^{\circ} \mathrm{C}\right)$ as shown in figure insets.

\section{Thermal stability}

Thermal stability analysis is an important experiment as it provides information of the lower and highest temperature that a protein can sustain its operational activity. The careful preparation of the enzyme formulation could be exploited in the context to reduce cost of the biofuel production. For example, when dealing with thick greasy feedstocks for biodiesel production, a slighty elevated temperature can improve the mass transfer by lowering the viscosity of the oil (Pramanik, 2003).

For thermal stability analysis, samples were immersed in buffer or in n-heptane and their residual activities were calculated after incubation at various temperatures for $30 \mathrm{~min}$ (Fig. S6). The highest obtained residual activity was at $30^{\circ} \mathrm{C}$ but no significant differences in sample activities were observed from 20-40 ${ }^{\circ} \mathrm{C}$ (Fig. S6a inset). Activity then dropped significantly at higher temperatures, but CLNP and cNP-mNP were somewhat more stable than the lipase itself, which in turn improved NP operational stability. A similar trend was observed under non-aqueous conditions which are more relevant for biodiesel formation (Fig. S6b). Again, no significant difference was observed for any sample from $20-40{ }^{\circ} \mathrm{C}$. However, increased stability of all formulations was evident at higher temperatures when compared to aqueous conditions. At $60-70{ }^{\circ} \mathrm{C}$, overall residual activities of all samples were roughly 10 -times higher than under aqueous conditions. These findings confirm that the conjugation of the protein on a carrier increased its thermal stability (Arroyo et al., 1999; Branco et al., 2015). This effect was more pronounced in the organic solvent because proteins have a much more rigid conformation in them (Klibanov, 2001). These results are important because they show that more rigid enzyme NP could be used for applications where elevated temperatures are advantageous.

\section{References}

[1] Arroyo, M., Sánchez-Montero, J.M.A., Sinisterra, J.V., 1999. Thermal stabilization of immobilized lipase B from Candida antarctica on different supports: effect of water activity on enzymatic activity in organic media. Enzyme Microb. Technol. 24 3-12.

[2] Branco, R.V., Gutarra, M.L., Guisan, J.M., Freire, D.M., Almeida, R.V., Palomo, J.M., 2015. Improving the thermostability and optimal temperature of a lipase from the hyperthermophilic archaeon Pyrococcus furiosus by covalent immobilization. BioMed Res. Int. 2015

[3] Klibanov, A.M., 2001. Improving enzymes by using them in organic solvents. Nature. 409(6817), 241.

[4] Pramanik, K., 2003. Properties and use of Jatropha curcas oil and diesel fuel blends in compression ignition engine. Renewable Energy. 28, 239-48. 